\title{
Spatial Price Differences in China: Estimates and Implications
}

\author{
LOREN BRANDT \\ University of Toronto \\ CARSTEN A. HOLZ \\ Hong Kong University of Science and Technology
}

\section{Introduction}

Price indices are standard statistical data that are constructed by statistical authorities across all countries. The key price index often is the Consumer Price Index (CPI). In the United States, for example, the CPI serves as an economic indicator used in formulating fiscal and monetary policy, as a deflator of other economic series (e.g., retail sales or hourly and weekly earnings), and as a means of adjusting dollar values (e.g., when social security benefits are indexed using the CPI). ${ }^{1}$ But while the calculation and use of price indices are widespread, absolute price comparisons across localities are usually not possible. Thus, in the United States, the Bureau of Labor Statistics compiles a nationwide urban CPI based on about 80,000 prices recorded in 87 urban areas by aggregating individual commodity or area indices. ${ }^{2}$ The commodities are specific to the local outlets; no data are collected on the prices of one nationwide identically defined commodity in different areas of the United States. A comparison of the absolute price level in one locality with that in another locality, thus, is not possible for the United States.

China's National Bureau of Statistics (NBS), like the Bureau of Labor Statistics in the United States, publishes a number of official price indices, including national and provincial CPIs, as well as separate CPIs for rural and urban areas at both the national and the provincial level. These price indices allow a comparison of the changes in the level of consumer prices over time across different localities but do not permit a comparison of absolute price

We are grateful for comments by two anonymous referees and extensive feedback from Thomas G. Rawski. Contact the corresponding author, Carsten A. Holz, at socholz@ust.hk.

${ }^{1}$ For more details, see BLS (2000).

${ }^{2}$ See http://www.bls.gov/cpi/cpifact2.htm, titled "How BLS Measures Changes in Consumer Prices." The Bureau of Labor Statistics does not compile a rural CPI.

(C) 2006 by The University of Chicago. All rights reserved. 0013-0079/2006/5501-0003\$10.00 
levels between different localities at a given point in time. Like the Bureau of Labor Statistics, the NBS does not publish data on the individual prices and quantities underlying the provincial price indices it constructs.

The ability to compare the absolute price level across localities at a point in time can be important, however. In China, as in other countries, urban prices are systematically higher than rural prices for similar products, so failure to deflate urban and rural incomes in urban-rural income comparisons exaggerates the income gap. Similarly, prices in rural (urban) areas are not necessarily uniform across provinces; price differences can reflect a host of factors such as transportation costs or barriers to trade. Such price differences imply that comparisons of the relative purchasing power of incomes across provinces, if not spatially deflated, are biased.

At the country level, Kravis and Lipsey (1988) provide a theoretical argument for a positive correlation between the price level and income, in that prices of nontradable goods are higher, relative to prices of tradables, in rich countries than in poor countries. Their empirical analysis across countries confirms their argument. In the context of China, this implies that the absolute price level can be expected to be higher in provinces in which nominal income is higher, for example, Guangdong, than in low-income provinces, for example, Gansu, because nontradables, such as housing and services, are likely to be more expensive in Guangdong than in Gansu. Simply comparing nominal income in the high-income to that in the low-income province, thus, would exaggerate the difference in the standard of living between the two provinces. ${ }^{3}$

Adjustments in income measures to take into account the local price level are immediately relevant for economic analysis such as inequality studies, wage comparisons, or assessments of poverty. A large body of literature attempts to measure inequality in China. These inequality studies measure inequality using a variety of income or consumption measures. ${ }^{4}$ But, given the absence of official

\footnotetext{
${ }^{3}$ The Statistical Yearbook 1996, 280, makes the lack of adjustment to income data for price differences very explicit. The table with time series and provincial data on per capita consumption (which, in this case, happen to be based on National Income Account data on consumption) comes with a note stating that "the ratio [of consumption of non-agricultural to agricultural residents] does not eliminate the effect of price differentials between urban and rural areas on consumption expenditure."

${ }^{4}$ Three types of (per capita) income measures dominate in the literature, with the occasionally small variation of an individual income measure (and some authors not providing an exact definition of their income measures). The first, most widely used income measure is household survey income as compiled by the NBS for rural and urban areas separately (see, e.g., Trescott 1985; Adelman and Sunding 1987; Knight and Song 1991; Howes 1993; Gustafsson and Shi 1998; or Yang 1999). In the rural case, household income includes the value of self-produced-self-consumed goods and services, with, alternatively, rural data also available for monetary income only. Literature using
} 
price level data, they are unable to adjust their income or consumption measures to take into account systematic differences in price levels across localities. ${ }^{5}$ If these differences were taken into account, inequality in China may well turn out to be significantly lower than these studies claim.

For a few years around 1990, the NBS published price data on specific products (defined uniformly across the country) in all provinces. At the time, China was still only emerging from the planned economy, and many industrial consumer goods were still subject to a central distribution system, making this endeavor feasible. ${ }^{6}$ We use these data to construct province-specific price levels that are comparable across localities (for rural areas in each province, urban areas, and the province in total). While we use 1990 as the base year, the absolute price levels for other years can be derived based on the calculated 1990 base-year basket cost combined with the CPIs of all other years. We provide year 2000 comparison data throughout the article and report spatial (price) deflators by province for the period between 1984 and 2004 in a spreadsheet available in the online edition of Economic Development and Cultural Change. These price levels can serve as adjustment factors to nominal income measures in studies that involve comparisons across provinces.

Our price level is designed to match household survey expenditures as compiled by the NBS; data on household survey expenditures also underlie the construction of the official CPI, which is used here to derive spatial price

rural monetary income only, or a close approximation, includes Hsiung and Putterman (1989) and Meng and Wu (1998). The Chinese Academy of Social Sciences, in a survey for 1988 and 1995, augmented the NBS definition of household income by including, among others, the rental value of housing and, in urban areas, furthermore, the in-kind income omitted by the NBS in its data. Literature using this income measure, or a close approximation, includes Khan et al. (1992, 1993), Bishop, Formby, and Zheng (1996), Kahn and Riskin (1998), and Khan, Griffin, and Riskin (1999). This augmented definition approaches the household consumption measure in the National Income Accounts, a second income measure that is also directly used in some inequality studies, with data provided by the NBS (see, e.g., Zhang and Kanbur 2001). The third income measure is GDP or, in early years when GDP data were not yet available, gross output value or net material product data (see, e.g., Knight and Song 1990; Rozelle 1994; Lyons 1998; Wei and Wu 2001; Kanbur and Zhang 2002).

${ }^{5}$ One exception is Chen and Ravallion (1996). They construct provincial poverty lines for four southeast provinces using province-specific unit values (or implicit prices) from the rural household survey to price a common reference consumption bundle.

${ }^{6}$ For details on the sources of our price data and on all types and sources of price data that we are aware of, see app. A (as explained at the end of this section), Sec. I, on sources and types of price data.

${ }^{7}$ We report the spatial deflators in the form of the province- and year-specific basket cost, i.e., the provincial price level. A comparison of basket cost across provinces in any one year reveals the price differences across provinces in that year. (See the Excel spreadsheet available in the electronic edition of Economic Development and Cultural Change.) 
levels for years other than 1990. Since household survey income equals expenditures plus net savings (and a few other items), the spatial price levels provided here are likely to be the most appropriate to spatially deflate household survey income. Other income measures vary little from this basic household survey income measure, and the spatial deflators provided here, thus, are likely to improve inequality calculations or income comparisons independent of the measure of income on which they are based. ${ }^{8}$

The construction of spatial deflators is related to the literature on poverty lines. A common method of setting poverty lines is the construction of a Laspeyres deflator, which provides the cost of a fixed reference bundle of goods. Ravallion and Chen (2004) is an illustration of this approach for urban and rural China using region-specific food bundles valued at province-level median unit values. The bundles themselves are based on spending patterns of households between the 15th and the 25th percentiles. Meng, Gregory, and Wang (2005) provide an alternative set of poverty lines for urban China in 1986-2000 that allows for substitution within and between commodity groups over time, which they argue has been an important feature of household consumption because of ongoing institutional reform. Our spatial deflators are not meant to match a specific income group, and we do not allow for local substitution but use a nationwide uniform basket.

This article depends on elaborate and at times highly complex data work. We explain the basic procedures and relegate further explanations to appendices A-D available in the online version of Economic Development and Cultural Change (which also has a spreadsheet with provincial price levels of all individual years 1984-2004).

\section{Methodology}

To compare the aggregate price levels across provinces, we proceed in three steps. First, we define a living expenditure basket as a list of products (goods and services) and their quantities purchased in the base year, 1990. Second, this basket is priced in each province for the base year. This results in the base-year price level in each province. Third, for time series comparisons, the provincial prices of this basket in other years are obtained using the provincial CPIs.

\section{A. Defining the Basket}

The 1990 basket comes in three variations: a (nationwide average, per capita) rural basket, to be priced in each province using rural prices; an urban basket,

${ }^{8}$ On the link between household survey living expenditures and income, see app. A, Sec. II, on income data. 
to be priced in each province using urban prices; and a "joint" (weighted rural-urban) basket that reflects the living expenditure patterns of the whole population, rural and urban, to be priced, separately, in the rural areas of each province, in the urban areas of each province, and province wide (one joint basket, three types of pricing regimes).

A primary purpose of the use of a spatial deflator is to examine the impact of price differentials between provinces on the comparative purchasing power of provincial incomes. Thus, the provincial price levels we calculate, and the basket(s) on which they are based, should match the income measures used in the literature. Since a number of alternative income measures are used in the literature, in principle, a slightly different basket (and thus, spatial deflator) could be constructed for each income measure. In this article, we limit ourselves to the most widely used income measure, namely, household income as compiled by the NBS through separate rural and urban household surveys, and construct the basket using the corresponding household survey per capita living expenditure data. These living expenditure data determine the relative weight of different product categories in the (per capita) basket. At the nationwide level, by design, the value of the basket equals the corresponding nationwide average per capita living expenditures.

A "basket" is a list of products with product quantities and category-specific adjustment factors. The quantity data on products and the corresponding nationwide average price data are combined to reconstruct the value of each product category in per capita living expenditures, such as foods or consumer durables, as much as possible. While households consume hundreds of different products, we do not have a complete list of quantities and prices for all individual items (we are able to cover approximately 40 in the rural and 60 in the urban case). As a result, we are not able to "reconstitute" fully each of the various product categories. For each product category, we need to use an appropriate adjustment factor to make the sum of the purchasing values of the products on which we have data (sum of quantity times price across products within one category) equal to the average nationwide per capita living expenditure value for this product category.

For example, without expenditure data on all consumer durables, we take the de facto major consumer durables on which both quantity data and price data are available. The per capita purchasing value of these consumer durables, at nationwide prices, is then multiplied by an adjustment factor so that it is equal to the total value of this particular product category (expenditures on consumer durables) in the household survey on living expenditures. In other words, within each product category, those products on which quantities and prices are available are overweighted in order to make up for the absence of 
data on other products. This practice ensures that the different product categories in the basket are given their correct (nationwide average) relative weights to properly reflect the relative size of household expenditures in different product categories. We explain our procedures in detail below for the rural basket.

The living expenditure data come with one complication. The NBS compiles data on household living expenditures through separate rural and urban household surveys. The rural household survey collects data separately on monetary (cash) expenditures and on total household expenditures; the implicit difference constitutes self-produced-self-consumed (or in-kind) products. The published NBS statistics report both rural per capita total living expenditures and rural per capita monetary living expenditures. Our rural basket covers total rural household living expenditures to match the corresponding rural household survey income, which includes imputed income from self-produced-self-consumed products.

In the urban case, the urban household survey also collects data on monetary and in-kind expenditures; however, the published urban living expenditure data cover only monetary living expenditures. Similarly, the urban household survey income does not include in-kind income. Our urban basket by necessity covers monetary expenditures only; this matches the coverage of urban household survey income. ${ }^{?}$

We also construct a nationwide joint (weighted rural-urban) basket to, among others, derive a deflator for average (weighted rural-urban) per capita household income; such a spatial deflator is needed, for example, to compare provincial average income, or rural versus urban income within one province. The fact that the coverage of rural and urban income differs slightly implies that per capita income levels in rural areas are not fully comparable to those in urban areas and that a weighted rural-urban average income is therefore likely to be biased in favor of rural areas. In terms of spatially deflating income values, the joint living expenditure basket, based on total rural per capita living expenditures and monetary urban per capita living expenditures, reflects

\footnotetext{
${ }^{9}$ The potential bias in the urban data due to the lack of data on self-produced-self-consumed products is likely to be small. In the provinces with the most urbanized rural areas, e.g., Beijing, Shanghai, and Tianjin, the difference between total and monetary rural living expenditures (following the new imputation prices, explained below) was equal to only $13.91 \%, 23.85 \%$, and $23.77 \%$, respectively, of total rural living expenditures in 1990 , compared to a nationwide average of $35.90 \%$. However, most urban households are likely to benefit from another type of in-kind income, namely, subsidies for education, housing, transport, or health care, etc. The urban living expenditure data available do not capture these subsidies.
} 
exactly the same bias, as do the published income data and any average income constructed from them.

\section{B. Pricing the Baskets at the Provincial Level in a Base Year}

In a second step, we ask how much each basket costs in each province. Pricing the list of individual products with their (nationwide uniform) quantities, as specified in the basket, at the provincial prices, applying the (nationwide uniform) adjustment factors for each product category, and summing up across all product categories yields the provincial basket cost. These procedures are explained below in detail for the rural basket. The basket cost says how much a nationwide standard basket of goods and services, purchased by the typical household, costs in this provinces. This is the price level, or the comparable cost of living, for the particular province.

One complication, in the rural case, is that rural prices are not available for all products consumed in rural areas. For example, we do not have separate rural and urban prices for clothing and consumer durables and, therefore, end up using use the same product prices for both rural and urban areas (the retail prices in the provincial capital cities). Insofar as the relationship between rural and urban prices for these goods differs across provinces, this may introduce some bias into the spatial deflators. ${ }^{10}$ In the case of the rural living expenditures, three categories for which we have separate rural (in contrast to urban) prices for 1990, namely, foods (with the exception of a few individual food products), housing, and services, constitute $56.80 \%$ of rural living expenditures in that year. ${ }^{11}$

The base year for pricing the basket is 1990. The limited availability (across years) of absolute price data narrowed the choice of base years to half a dozen years, while the availability of related statistical data and practical considerations then led to the choice of $1990 .^{12}$

\section{Pricing the Basket at the Provincial Level in Other Years}

With absolute price data no longer published after 1993, baskets after 1993 can no longer be priced at the provincial level or in rural and urban areas

${ }^{10}$ For example, if in one province the (unknown) rural price of a specific consumer durable is much below the (known) price of this consumer durable in the provincial capital city but, in a second province, is equal to the price in the capital city, then by using the prices of provincial capital cities we overestimate the rural price level in the first province relative to the second province. Even though the same prices of these products are used to price the rural and urban baskets, the category (living expenditure) weights differ in the two baskets.

${ }^{11}$ See Rural Statistical Yearbook 1992, 219, and table 1. The percentage is net of those food products for which provincial capital city retail prices are used. For details on data sources for prices and on types of prices, see app. A, Sec. I.

${ }^{12}$ For details on the choice of base year, see app. A, Sec. III. 
within provinces. This problem is overcome by making use of existing official deflators for all years other than 1990. Multiplying the base year (1990) basket cost of a particular province by the relevant provincial CPI series yields the basket costs for this province in all other years.

The relative weights (quantities) of different products in the official CPI are based on the household living expenditure survey data, and the CPI, thus, matches the coverage of the basket. ${ }^{13}$ One complication is that the weights used by the NBS to construct the (rural, urban, total) CPI from its various components are almost certainly based on the monetary living expenditures only. ${ }^{14}$ This implies that rural self-produced-self-consumed products are underrepresented in the rural CPI. This matters when prices of self-producedself-consumed products, mainly grain, change by a different percentage than the average price of all products that were purchased using money. In the urban case, this problem does not arise because the urban household living expenditures (and, similarly, urban household income) do not include selfproduced-self-consumed products (or products received without monetary payment in exchange). ${ }^{15}$ We re-weight the rural CPI to take into account rural self-produced-self-consumed products in an alternative rural CPI and report and use both, the official and the re-weighted CPI, in the tables.

Three provinces, Tibet, Hainan, and Chongqing (established in 1997 through its separation from Sichuan), pose problems either in pricing the basket or in applying the CPI to obtain price levels for other years. The approximations of absolute prices in the case of Tibet, Hainan, and Chongqing are extensive. ${ }^{16}$ For the four provincial-level municipalities Beijing, Shanghai,

${ }^{13}$ In the published, somewhat aggregated data, the first seven of eight categories of the CPI and of living expenditures cover the same types of products, but in the case of the CPI they are limited to goods (i.e., excluding services); the eighth CPI category, then, is services, while the eighth living expenditure category is "others." The NBS, in calculating the CPI, presumably makes use of the numerous, mainly unpublished sub- (and sub-sub-) categories of the CPI and of living expenditures. The slight mismatch means that we are unable to construct our own Laspeyres (or Paasche, or Fischer, or Törnqvist) CPI from subindices of the official CPI. The weighting in the official CPI is likely to change either approximately every $6-8$ years or more frequently. The official CPI is based on separate rural and urban weighting schemes, with provinces allowed to vary slightly in their choice of weights. For details, see app. A, Sec. IV, on the derivation of price levels for years other than 1990.

${ }^{14}$ Appendix B, Sec. VI, on the adjustment of the rural CPI, provides evidence strongly suggesting that the official rural CPI is based on the monetary living expenditures only.

${ }^{15}$ The problem, of unknown size, in the urban case is that some urban households may benefit from subsidized education, housing, transport, or health care, etc. If these were included at full cost in the urban living expenditure data, this might imply a different weighting of living expenditure categories and thus of the CPI subindices.

${ }^{16}$ Appendices B, Sec. II, and C, Sec. I, on the construction of the rural and urban living expenditure baskets, provide details on how missing data are approximated. 
Tianjin, and, since 1997, Chongqing, no official rural CPIs are published and only municipality-wide, that is, provincial-level CPIs are reported; the same values are also officially reported as "urban" CPIs. In the case of these four municipalities, the rural CPI used here is the official municipal/urban CPI. Overall, the reader may wish to ignore Tibet, Hainan, and Chongqing throughout and, in addition, Beijing, Tianjin, and Shanghai in the rural case.

Based on the three baskets - rural, urban, and total-we derive five price levels for all years, 1984-2004: two for rural areas in each province (one based on the rural basket and one based on the joint basket, in each case pricing the basket at rural prices), similarly, two for urban areas in each province (one based on the urban basket and one based on the joint basket, in each case pricing the basket at urban prices), and one for each province in total (based on the joint basket and province-wide prices). In the following, we explain the construction of the rural living expenditure basket at some length; with the procedures similar for all baskets, discussion of the urban and joint baskets is kept much shorter.

\section{Rural Living Expenditure Price Level}

Construction of the rural living expenditure price level follows the three steps outlined above: establishment of the rural basket, pricing of the rural basket across provinces at rural prices, and derivation of provincial-level rural basket costs in other years.

\section{A. The Basket}

Table 1 provides a complete list of all product categories in rural household living expenditures together with the individual products for which quantity and price data are available. The table starts with total (per capita) rural household living expenditures and breaks these down into the different product categories. For each category, the table lists the total value of expenditures followed by a list of those products for which both quantity and price data are available. For an individual product, the average quantity consumed multiplied by the price yields the value of the expenditures for this product (per capita in rural households). The sum of the values across all products in a particular category is reported in the second-to-last column of the row with the official living expenditure figure for that category. The two figures should match in order for the basket to have the correct proportions across different product categories. But except in the case of implicit pricing (explained below), the two do not match because we do not have a complete list of quantities and prices for all products consumed by households in a particular category. In order for the two to match, we multiply the sum of individual product 
TABLE 1

PER CAPITA RURAL LIVING EXPENDITURE BASKET, 1990

\begin{tabular}{|c|c|c|c|c|c|}
\hline & $\begin{array}{l}\text { Living Expenditure } \\
\text { (Yuan) }\end{array}$ & Quantity Consumed & $\begin{array}{c}\text { Nationwide Average Price (in Yuan) } \\
\text { per Unit of the Product }\end{array}$ & $\begin{array}{l}\text { Value Covered } \\
\text { (Yuan) }\end{array}$ & $\begin{array}{l}\text { Adjustment } \\
\text { Factor }\end{array}$ \\
\hline $\begin{array}{l}\text { Total } \\
\text { A. Consumer goods }\end{array}$ & $\begin{array}{l}584.63 \\
544.23\end{array}$ & & & & \\
\hline 1. Foods & 339.30 & Kilograms & & & \\
\hline a. Staples (i or ii) & 135.47 & 262.08 & & & \\
\hline i) Implicit & & 262.08 & Implicit price .5169 & 135.47 & 1.0000 \\
\hline ii) Composite & & 262.08 & Composite of four procurement prices .6812 & 178.53 & .7588 \\
\hline b. All others & 203.83 & & & 194.79 & 1.0464 \\
\hline Vegetables & & 134.00 & Price implicit in urban living expenditure data .57 & 76.38 & \\
\hline Edible oil & & 5.17 & Procurement price of rapeseed oil 1.4893 & 7.70 & \\
\hline Poultry & & 1.26 & Procurement price $/ \mathrm{kg}$ of live poultry 6.3605 & 8.01 & \\
\hline Eggs & & 2.41 & Procurement price 4.2939 & 10.35 & \\
\hline Fish, shrimp & & 2.13 & Procurement price of silver carp 2.8732 & 6.12 & \\
\hline Sugar & & 1.50 & Retail price (baishatang) 2.666 & 4.00 & \\
\hline Alcohol & & 6.14 & Composite retail price: hard liquor, beer 2.2721 & 13.95 & \\
\hline Meat & & 11.34 & Procurement price of pork and beef 3.4961 & 39.65 & \\
\hline Tobacco & & 27.38 & Composite retail price of three grades .5840 & 15.99 & \\
\hline Tea leaves & & .27 & Composite retail price: jasmine, black, green 20.0487 & 5.41 & \\
\hline Fruit & & 5.89 & Composite procurement price of 4 items 1.0208 & 6.01 & \\
\hline Milk & & 1.08 & Retail price 1.127 & 1.22 & \\
\hline 2. Clothing & 45.34 & Meters & Retail Prices & 38.11 & 1.1898 \\
\hline Cotton cloth & & .90 & 3.129 & 2.82 & \\
\hline Cotton (natural) & & $.31 \mathrm{~kg}$ & 8.659 & 2.68 & \\
\hline Chemical fiber & & 1.74 & 7.765 & 13.51 & \\
\hline Nylon & & .08 & 31.7504 & 2.54 & \\
\hline Silk & & .04 & 19.3526 & .77 & \\
\hline Wool products & & .07 & 59.726 & 4.18 & \\
\hline Shoes & & .67 pairs & Composite retail price of four types of shoes 17.3164 & 11.60 & \\
\hline
\end{tabular}


3. Housing (i or ii) i) Implicit

ii) Composit

Cement

Wood planks

Glass

Bricks

4. Energy

5. Articles for daily use

a. Consumer durables

Bicycle

Sewing machine

Clock

Watch

Fan

Washing machine

Refrigerator

Sofa

Cloth stand

Desk

Black and white TV

Color TV

Radio recorder

b. Medicine/hygien

B. Services
69.30

$.5625 \mathrm{~m}^{2}$

Implicit price of $1 \mathrm{~m}^{2}$ of newly constructed household buildings 123.21

$$
\begin{gathered}
.1944 \\
873.96 \\
9.19 \\
.0977
\end{gathered}
$$

$.0682 \mathrm{~m}^{2}$

186.1901

26.46

$544.5365 \mathrm{~kg}$

Retail price of $100 \mathrm{~kg}$ coal 4.8592

Items per 100 Persons

2.6529

1.0730
.8779

.8779
2.6637

2.6637

2.0201

.3183

1.0811

1.2573

1.6094

1.2588

.0131
1.6908

.2777

276.786

253.047
43.4643

43.4643
51.668

51.668
273.308

273.308
532.965

$1,697.7572$

349.89

315.908

202.0268
28.852

540.037

, 440.06

13.23

.031996 years

13.23
40.40

Composite retail price; by design 1.0000

Annual industrial TVE wages per laborer 1,262.68

69.30

1.0000

1.6509

6.90

6.90
16.25
.63

18.20

1.0000

$51.15 \quad .9892$

7.34

.38

1.38

5.52

1.70
1.38

4.40

5.08

5.08
2.54

.00

9.13

2.81

13.23

40.40

1.0000

1.0000

Sources. Living expenditures: Statistical Yearbook 1992, 310. Quantities of major consumer goods consumed: Statistical Yearbook 1991, 303; Rural Statistical Yearbook 1991, 221; and Rural Household Survey Yearbook 2002, 15-16. Procurement prices and retail prices of individual goods: Price Statistical Yearbook 1991. Implicit price of via construction costs: Istical Yearbook 192, 221, 232. Implicit vegetable price in urban expenditures. Urban Household Survey Yearbook 1990, 124. Implicit housing costs Not Published data a re report with as many decimals as in the

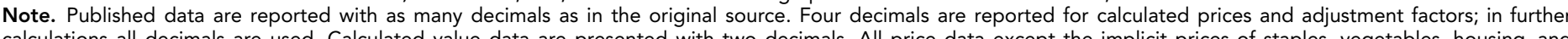
calculations all decinals are used. Calculated value data are present

further details, including on specific products, see app. B, Sec. It, on the construction of the rural living expenditure basket. 
values within a category by whatever adjustment factor it takes to make the aggregate value of products in this category equal to the corresponding living expenditure figure. The adjustment factor is reported in the last column.

For example, in the product category "clothing," the average rural household in 1990 consumed 0.90 meters of cotton cloth per capita, for which it paid 3.129 yuan per meter; the value of cotton cloth purchased is 2.82 yuan per capita (0.90 times 3.129). Summing up the values of all different clothing products purchased yields per capita expenditures on clothing of 38.11 yuan. However, the official rural living expenditure data from the household surveys show total rural per capita living expenditures on clothing to be 45.34 yuan. Thus, we adjust expenditures on our selective list of products within the clothing category by a factor of 1.1898 so that total expenditures on clothing, or 38.11 yuan times 1.1898 , equal 45.34 yuan. $^{17}$

Table 1 reports not only quantities and adjustment factors but also nationwide (rural) prices, since these are needed to derive the adjustment factors in the first place. Applying the nationwide rural prices to the basket, that is, to the set of products with quantities and product category adjustment factors, necessarily yields a basket cost exactly equal to the nationwide rural total (monetary and in-kind) per capita living expenditures of 584.63 yuan. Pricing this basket at provincial-level prices-see the next section-yields the provincial-level cost of the nationwide uniform rural living expenditure basket, that is, the particular provincial price level.

Construction of table 1 involved a number of choices: (a) between two living expenditure classification schemes available for 1990 (the earlier one is used), (b) between two values for rural living expenditures (and their product categories) depending on whether the NBS applies old or new imputation prices to self-produced-self-consumed products (the one based on new imputation prices is used), (c) between two different methods for calculating the prices of staples and housing, and $(d)$ between procurement versus retail prices of agricultural goods. The first two choices are further explained and justified in an appendix. ${ }^{18}$

Two sets of prices to value staples (grain) are the following. One is the implicit price of staples obtained by dividing per capita rural living expenditures for staples by the per capita quantity of rural consumption of staples. A second approach is to make assumptions about the relative shares of different staples in the nationwide average rural per capita quantity of staples consumed

\footnotetext{
${ }^{17}$ Adjustment factors are specific to product categories, not individual products. In the category foods, the two subcategories "staples" and "all others" are treated separately, with two separate adjustment factors.

${ }^{18}$ See app. A, Sec. V, on expenditure classification schemes and imputation prices.
} 
and to apply these shares to the procurement prices of the individual types of staples in order to obtain a composite price. An adjustment factor is derived by comparing the value of the "nationwide composite price times nationwide rural per capita quantity of staples" with the nationwide rural per capita living expenditures on staples. For the two prices, see table $1 .{ }^{19}$

In the case of housing, lacking data on rent (or land prices or real estate prices), one approach is to utilize information on construction costs per square meter of rural household buildings. At the nationwide average rural construction costs per square meter, nationwide per capita rural household living expenditures on housing are equal to the cost of 0.5625 square meters of new household buildings. These 0.5625 square meters are the quantity of housing to be included in the basket; priced at the nationwide rural construction costs, the value (price times quantity) equals the living expenditures for housing. ${ }^{20}$ This approach is equivalent to using rent if the relationship of rent to construction costs is constant across provinces. An alternative approach is to use the available rural quantity and price data on four types of construction materials, which yield a value equal to almost two-thirds of housing expenditures and then to apply an adjustment factor to make up for the gap.

We proceed with the first approach of implicit prices for both staples and housing. Using composite prices yields similar variation in the (total) basket cost across provinces in $1990 .^{21}$

In the case of several foods (other than staples) the question arises as to whether the agricultural procurement price or the retail price is more appropriate. $^{22}$ Thus, in the case of meat, presumably almost all rural households

${ }^{19}$ For further details on rural staples prices, see app. B, Sec. I. At the nationwide level, the derived composite price of $0.6812 \mathrm{yuan} / \mathrm{kg}$ of staples is almost one-third larger than the implicit price. Multiplying the nationwide composite price with the quantity of staples consumed yields a consumption value of 178.53 yuan that exceeds the rural living expenditures on staples of 135.47 yuan. An adjustment factor of 0.7588 is needed to reduce 178.53 yuan to 135.47 yuan.

${ }^{20}$ Pricing this quantity of 0.5625 square meters per capita in a particular province at the provincial construction costs per square meter then yields a province-specific expenditure level for housing. For further considerations in the calculation of this implicit price, including details on the coverage of "rural household buildings" and why this particular variable was chosen, see app. B, Sec. II, on the construction of the rural living expenditure basket.

${ }^{21}$ The 1990 rural basket costs across provinces with staples and housing priced at composite prices are provided in app. B, Sec. III. The other two pricing versions, where either staples or housing are priced at implicit prices and the other at composite prices, are not reported since they do not provide any additional information; the price levels in the four versions are highly correlated across provinces (at the $0.1 \%$ significance level for each pair of versions, in 1990 and in 2000). The version reported here (using implicit prices) and the version reported in app. B, Sec. III (using composite prices), for most provinces cover the widest range of values.

22 The agricultural procurement price is the price for agricultural products paid by industrial and commercial enterprises, other units, and individuals when purchasing agricultural products from farmers or state-owned agricultural production units (Liu, Liu, and Jin 2000, 110). 
throughout China produce their own meat, and the procurement price, that is, the price they can receive when selling the meat, appears the appropriate one to price the mostly self-produced-self-consumed meat. Even if some rural households were to not raise livestock, they are likely to be able to buy meat from other rural households at a price close to the procurement price. ${ }^{23}$ For yet other foods, such as tobacco or tea, the retail price appears more appropriate than the agricultural procurement price. Tobacco and tea are grown only in a few provinces, and most farmers across the country will be purchasing the manufactured product (at retail prices). Even those farmers who harvest tobacco or tea leaves do not necessarily turn them into cigarettes and tea for their own use. The type of price used for each product is explicitly stated in table 1.

No price or quantity data are available for services and energy, and no quantity data for consumer durables. ${ }^{24}$ We assume that the cost of services depends solely on the cost of labor and that the average service provider earns the rural average industrial wage or an across-provinces constant fraction thereof. Relating 1990 nationwide average rural household living expenditures on services to average annual industrial township and village enterprise (TVE) wages per laborer shows service expenditures to be equivalent to 0.0320 labor years in industrial TVEs. This quantity of 0.0320 labor years can then later be priced at the province-specific average annual industrial TVE wage. In the case of energy, we assume that all energy expenses are on coal. At the national level, the nationwide average per capita rural expenses on energy in 1990 would have bought 544.5365 kilograms of coal, which then is the quantity to later be priced in each province. ${ }^{25}$ In the case of consumer durables, we approximate purchases by the annual change in the stock of consumer durables between 1989 and $1990 .^{26}$

${ }^{23}$ For further considerations in the choice of meat prices, see app. B, Sec. II, on the construction of the rural living expenditure basket.

${ }^{24}$ For details in the case of "medicine/hygiene," item $5 \mathrm{~b}$ in table 1, see app. B, Sec. II, on the construction of the rural living expenditure basket.

${ }^{25}$ In the case of coal and, later, for the urban basket, also gas, the published nationwide price in the derivation of the quantity-(per capita) living expenditures divided by nationwide price equals the (per capita) quantity to be included in the basket-is replaced by the average price across provinces. For most retail goods, the mean price across the 29 provincial capitals is within a few percentage points of the published nationwide retail price, but not so for coal and gas. In the case of coal, the nationwide retail price is $63.69 \%$ higher than the arithmetic mean across the 29 provincial capitals, with the price in none of the 29 provincial capitals higher than the nationwide price; in the case of gas, the nationwide price is 2.0476 times higher than the mean, with the price in two out of the 20 provincial capitals higher than the nationwide price (Price Statistical Yearbook 1991, 147, 303-4).

${ }^{26}$ For further details, see app. B, Sec. IV, on rural quantities of consumer durables. 


\section{B. Pricing the Rural Basket at the Provincial Level in 1990}

The next step is to price the nationwide uniform basket in each province using provincial-level prices. Pricing the nationwide average per capita rural consumption quantities of the individual products given in table 1 at provincial rural prices, and applying the adjustment factors listed in table 1, yields the provincial cost of the nationwide uniform rural living expenditure basket. This is the provincial price level of the nationwide uniform basket. The specifications in table 1 on the particular type of nationwide price used in the construction of the basket also apply to the provincial-level prices. The cost of the nationwide uniform rural per capita living expenditure basket in each of China's provinces is reported in table $2 .^{27}$

In 1990, the cost of the nationwide uniform rural basket ranges from a low of 509.72 yuan in Sichuan to a high of 803.57 yuan in Guangdong, which is a difference of $57.65 \%$. What underlies the differences in the rural price levels across provinces in 1990? Table 3 reports descriptive statistics across provinces, for each product and for the major product categories. For foods, clothing, and the main consumer durables, the coefficients of variation are relatively low $(0.1051,0.1636,0.0664$, respectively). Among the foods, the coefficient of variation is lowest for basic goods such as staples, edible oil, sugar, and eggs but higher for items such as poultry, fish, or tea leaves. Two types of cloth in the clothing category have rather high coefficients of above 0.40 , but some of the variation may be due to unavoidable quality differences across provinces given the relatively broad product specification. The low variation in the prices of consumer durables implies that the prices of these goods tend to be fairly uniform across the country. These are standard industrial products, with in 1990 perhaps only minimal product differentiation across the country.

The prices of energy and of the nontradable goods housing and services vary more widely across provinces. The coefficient of variation in the case of coal is 0.2844 . Implicit construction costs vary widely across provinces with a coefficient of variation of 0.3137 . The coefficient of variation of 0.2798 in the aggregate composite price of construction materials together with similarly high coefficients of variation for the prices of the individual construction materials suggests that the prices of the different construction materials vary

${ }^{27}$ Product-specific details to accompany table 2 are provided in app. B, Sec. V, on the provinciallevel pricing of the rural basket. 
TABLE 2

PRICE LEVEL OF RURAL BASKET ACROSS PROVINCES, 1990 AND 2000, YUAN

\begin{tabular}{|c|c|c|c|c|c|c|c|c|c|c|}
\hline & \multicolumn{2}{|c|}{1990} & \multicolumn{3}{|c|}{2000} & \multicolumn{3}{|c|}{2000} & \multicolumn{2}{|c|}{$\begin{array}{l}\text { Reference: Rural } \\
\text { Net Income }\end{array}$} \\
\hline & $\begin{array}{c}\text { Basket Cost } \\
\text { (Yuan) }\end{array}$ & Ratio & $\begin{array}{l}\text { Official Rural CPI } \\
2000 / 1990\end{array}$ & $\begin{array}{c}\text { Basket Cost } \\
\text { (Yuan) }\end{array}$ & Ratio & $\begin{array}{l}\text { Adjusted Rural CPI } \\
2000 / 1990\end{array}$ & $\begin{array}{c}\text { Basket Cost } \\
\text { (Yuan) }\end{array}$ & Ratio & 1990 & 2000 \\
\hline Total & 584.63 & 1.00 & 1.9025 & $1,112.24$ & 1.00 & 2.0290 & $1,186.22$ & 1.00 & 686 & 2,253 \\
\hline Beijing & 710.88 & 1.22 & 2.6864 & $1,909.68$ & 1.72 & 2.6864 & $1,909.69$ & 1.61 & 1,297 & 4,605 \\
\hline Tianjin & 656.72 & 1.12 & 2.2735 & $1,493.04$ & 1.34 & 2.2735 & $1,493.03$ & 1.26 & 1,069 & 3,622 \\
\hline Hebei & 585.44 & 1.00 & 1.7051 & 998.23 & .90 & 1.8123 & $1,060.99$ & .89 & 622 & 2,479 \\
\hline Shanxi & 602.18 & 1.03 & 1.9533 & $1,176.22$ & 1.06 & 1.9337 & $1,164.41$ & .98 & 604 & 1,906 \\
\hline Neimenggu & 563.94 & .96 & 1.9165 & $1,080.77$ & .97 & 2.0348 & $1,147.52$ & .97 & 607 & 2,038 \\
\hline Liaoning & 610.66 & 1.04 & 1.7487 & $1,067.88$ & .96 & 1.8266 & $1,115.42$ & .94 & 836 & 2,356 \\
\hline Jilin & 627.30 & 1.07 & 1.7157 & $1,076.25$ & .97 & 1.8613 & $1,167.56$ & .98 & 804 & 2,023 \\
\hline Heilongjiang & 595.50 & 1.02 & 1.8316 & $1,090.69$ & .98 & 1.9317 & $1,150.30$ & .97 & 760 & 2,148 \\
\hline Shanghai & 730.23 & 1.25 & 2.5095 & $1,832.52$ & 1.65 & 2.5095 & $1,832.51$ & 1.54 & 1,907 & 5,596 \\
\hline Jiangsu & 623.41 & 1.07 & 1.8729 & $1,167.57$ & 1.05 & 2.0537 & $1,280.27$ & 1.08 & 959 & 3,595 \\
\hline Zhejiang & 612.06 & 1.05 & 1.9614 & $1,200.47$ & 1.08 & 2.0533 & $1,256.72$ & 1.06 & 1,099 & 4,254 \\
\hline Anhui & 536.23 & .92 & 2.0251 & $1,085.91$ & .98 & 2.3767 & $1,274.45$ & 1.07 & 539 & 1,935 \\
\hline Fujian & 641.31 & 1.10 & 1.8659 & $1,196.59$ & 1.08 & 1.9631 & $1,258.97$ & 1.06 & 764 & 3,230 \\
\hline Jiangxi & 569.70 & .97 & 1.8869 & $1,074.94$ & .97 & 2.0726 & $1,180.76$ & 1.00 & 670 & 2,135 \\
\hline Shandong & 577.67 & .99 & 1.8694 & $1,079.89$ & .97 & 2.0146 & $1,163.78$ & .98 & 680 & 2,659 \\
\hline Henan & 562.16 & .96 & 1.7569 & 987.63 & .89 & 1.9543 & $1,098.61$ & .93 & 527 & 1,986 \\
\hline Hubei & 528.44 & .90 & 2.0935 & $1,106.28$ & .99 & 2.3516 & $1,242.66$ & 1.05 & 671 & 2,269 \\
\hline Hunan & 569.14 & .97 & 2.2335 & $1,271.19$ & 1.14 & 2.5035 & $1,424.87$ & 1.20 & 664 & 2,197 \\
\hline Guangdong & 803.57 & 1.37 & 1.8670 & $1,500.29$ & 1.35 & 1.8655 & $1,499.09$ & 1.26 & 1,043 & 3,654 \\
\hline Guangxi & 602.46 & 1.03 & 1.9863 & $1,196.65$ & 1.08 & 2.2109 & $1,332.00$ & 1.12 & 639 & 1,865 \\
\hline Hainan & 708.37 & 1.21 & 1.8699 & $1,324.60$ & 1.19 & 2.1274 & $1,507.01$ & 1.27 & 696 & 2,182 \\
\hline Sichuan & 509.72 & .87 & 2.0503 & $1,045.08$ & .94 & 2.2029 & $1,122.86$ & .95 & 558 & 1,904 \\
\hline Guizhou & 592.75 & 1.01 & 2.2317 & $1,322.83$ & 1.19 & 2.6301 & $1,559.01$ & 1.31 & 435 & 1,374 \\
\hline Yunnan & 609.39 & 1.04 & 2.2785 & $1,388.49$ & 1.25 & 2.4060 & $1,466.19$ & 1.24 & 541 & 1,479 \\
\hline Tibet & 673.27 & 1.15 & 1.9874 & $1,338.07$ & 1.20 & 2.0150 & $1,356.64$ & 1.14 & 650 & 1,331 \\
\hline Shaanxi & 592.96 & 1.01 & 2.1133 & $1,253.08$ & 1.13 & 2.5956 & $1,539.09$ & 1.30 & 531 & 1,444 \\
\hline Gansu & 573.76 & .98 & 2.0992 & $1,204.45$ & 1.08 & 2.4643 & $1,413.90$ & 1.19 & 431 & 1,429 \\
\hline
\end{tabular}




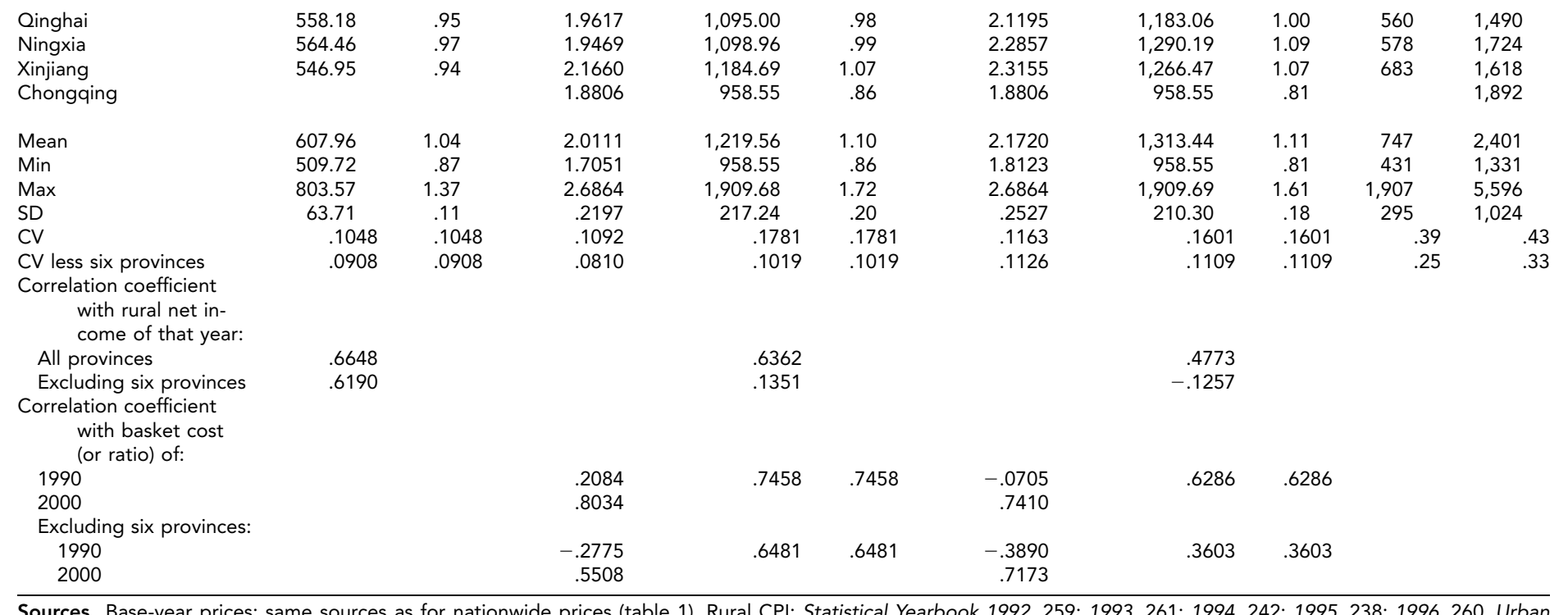

Sources. Base-year prices: same sources as for nationwide prices (table 1). Rural CPI: Statistical Yearbook 1992, 259; 1993, 261; 1994, 242; 1995, 238; 1996, 260. Urban
Household Survey Yearbook 1997,42 . Statistical Yearbook 1998, 306; 1999, 298; 2000, 294; 2001, 286. Adjusted rural CPI: see app. B, Sec. VI for the adjustment of the rural CPI. Rural net income: Statistical Yearbook 1992, 308 (at new imputation prices); 2001, 325.

Note. SD: standard deviation. CV: coefficient of variation. "Ratio" denotes the cost of the basket in a particular province relative to the nationwide cost of the basket. The nationwide basket cost is based on official nationwide per capita quantity and price data, as laid out in table 1 (quantities times adjustment factors times prices in table 1 yield the nationwide basket cost also reported here). The six provinces excluded in some rows at the bottom are Tibet and Hainan (due to incomplete data-for further details, see app. B, Sec. V. on provincial-level pricing of the rural basket), Chongqing (due to its emergence as a provincial-level entity in 1997 only and due to its largely urban character), and Beijing, Shanghai, and Tianjin (due to their largely urban character). For Beijing, Shanghai, Tianjin, and Chongqing, no rural CPls are available; the "official rural" CPIs in the table in these four cases (with further complications in the case of Chongging, explained in app. B, Sec. VI, on adjustment of the rural CPI) are the provincial-level (urban) CPIs. Prices of both staples and housing are implicit prices. A similar table where the prices of staples and housing are composite prices is provided in app. B, Sec. III. For income data, see the explanations in app. A, Sec. II. For further, product- and province-specific details, see app. B, Sec. V, on the provinciallevel pricing of the rural basket. For the choice of the type of individual prices, see table 1. 
TABLE 3

DRIVING FACTORS OF DIFFERENCES IN RURAL PRICE LEVELS ACROSS PROVINCES, 1990

\begin{tabular}{|c|c|c|c|c|c|c|}
\hline & \multirow[b]{2}{*}{ National Product Price } & \multicolumn{5}{|c|}{ Across Provinces: Product (or Category) Price } \\
\hline & & Mean & Min & Max & SD & $\mathrm{CV}$ \\
\hline \multicolumn{7}{|l|}{ Total } \\
\hline 1. Foods $(58.04 \%)$ & 339.30 & 352.23 & 300.76 & 442.76 & \multicolumn{2}{|c|}{ A. Consumer goods (93.09\%) } \\
\hline a. Staples $(23.17 \%)$ & & & & & & \\
\hline i) Implicit & 135.47 & 143.74 & 119.21 & 219.09 & 23.51 & .1636 \\
\hline ii) Composite & 178.53 & 203.31 & 164.19 & 276.35 & 28.91 & .1422 \\
\hline b. All others (34.86\%) & 194.79 & 199.24 & 163.78 & 286.75 & 30.15 & 1513 \\
\hline Vegetables & .57 & .59 & .32 & .96 & .15 & .2569 \\
\hline Edible oil & 1.49 & 1.50 & 1.07 & 1.93 & .17 & .1116 \\
\hline Poultry & 6.36 & 5.74 & 4.06 & 10.08 & 1.64 & 2855 \\
\hline Eggs & 4.29 & 4.70 & 3.32 & 6.76 & .86 & .1828 \\
\hline Fish, shrimp & 2.87 & 3.56 & 2.30 & 6.11 & .90 & 2540 \\
\hline Sugar & 2.67 & 2.56 & 2.36 & 2.80 & .09 & .0360 \\
\hline Alcohol & 2.27 & 2.22 & 1.32 & 3.69 & .51 & .2318 \\
\hline Meat & 3.50 & 3.50 & 2.55 & 5.52 & .70 & .2000 \\
\hline Tobacco & .63 & .59 & .41 & .94 & .10 & .1819 \\
\hline Tea leaves & 20.05 & 22.53 & 13.00 & 41.79 & 6.26 & .2778 \\
\hline Fruit & 1.02 & 1.07 & .56 & 1.63 & .25 & .2357 \\
\hline Milk & 1.13 & 1.14 & .76 & 2.00 & .23 & .2007 \\
\hline 2. Clothing $(7.76 \%)$ & 38.13 & 41.17 & 32.10 & 55.39 & 6.73 & .1636 \\
\hline Cotton cloth & 3.13 & 3.14 & 2.64 & 3.60 & .22 & .0693 \\
\hline Cotton (natural) & 8.66 & 9.75 & 6.00 & 13.00 & 1.62 & .1658 \\
\hline Chemical fiber & 7.77 & 9.36 & 4.05 & 18.03 & 3.83 & .4094 \\
\hline Nylon & 31.75 & 32.14 & 20.13 & 48.46 & 7.04 & .2189 \\
\hline Silk & 19.35 & 18.60 & 5.81 & 31.43 & 7.75 & .4168 \\
\hline Wool products & 59.73 & 58.59 & 46.60 & 70.93 & 5.60 & .0956 \\
\hline Shoes & 17.32 & 17.34 & 13.95 & 22.38 & 2.14 & .1232 \\
\hline
\end{tabular}


3. Housing (11.85\%)

(

ii) Composite

Cement

Wood planks

Glass

Bricks

4. Energy (4.53\%)

Coal $(100 \mathrm{~kg})$

5. Articles for daily use

a. Consumer durables

(8.66\%)

Sewing machine

Clock

Clock

Fan

Washing machin

Refrigerator

Sofa

Cloth stand

Desk

Black and white TV

Color TV

Radio recorder

b. Medicine/hygiene (2.26\%)

B. Services $(6.91 \%)$

Industrial TVE wages

69.30
41.98
.19
873.96
9.19
.10
26.46
7.95

$\begin{array}{rr}76.51 & 31.40 \\ 41.37 & 25.43 \\ .19 & .12 \\ 867.49 & 434.28 \\ 9.14 & 6.22 \\ .10 & .04 \\ 26.22 & 16.34 \\ 4.82 & 3.00\end{array}$

138.61
70.67
0.27
$1,743.75$
12.50
.17
43.63
8.01

24.00
11.58

$\begin{array}{ll}.3137 \\ -11.58 & .2798\end{array}$

329.50

$\begin{array}{ll}1.55 & .3798 \\ .04 & .1692\end{array}$

$\begin{array}{rr}.04 & .3509 \\ 7.46 & .2844\end{array}$

$\begin{array}{ll}7.46 & .2844 \\ 1.37 & .2844\end{array}$

Sources. See table 1.

Note. SD: standard deviation. CV: coefficient of variation. The percentages given in parentheses after the labels of the main product categories are the shares of these product categories in total rural living expenditures. For the absolute values, see table 1 . For the units of individual products, see table 1. When a national price for a product is lacking, the arithmetic mean across all provinces is used, including provinces whose values were imputed. (Chongqing data are never available and are not implicit price of staples and the aggregate price (value) of the second subcategory "all others," incorporating the small adus on implicit staples prices, conste

conditures). 
in step across provinces. ${ }^{28}$ Construction materials are likely to be produced locally and, thus, to reflect local costs, a fair share of which should be labor. Labor prices are also reflected in service prices, which show medium variation across provinces with a coefficient of variation of 0.2460 . The finding that the prices of nontradables vary more widely across provinces in China than the prices of almost all other product categories parallels the findings of Kravis and Lipsey (1988), mentioned in the introduction, across counties.

Housing, services, and energy's small share in the basket $(11.85 \%, 6.91 \%$, and $4.53 \%$, respectively) dampens their impact on the overall variation in basket costs, and some variation across product categories appears to cancel out. The coefficient of variation of basket costs, across provinces, was only around 0.1 in 1990 (table 2).

In 1990, across provinces, the basket cost is positively correlated with rural nominal net income at the $0.1 \%$ significance level; see the bottom rows of table 2 for the correlation coefficient, or figure $1 .{ }^{29}$ In other words, the cost of the rural basket, that is, the price level, is highest (lowest) in the provinces with highest (lowest) rural net income. This already indicates a need for spatial deflation in cross-province income comparisons.

\section{Pricing the Rural Basket over Time}

In a further step, the 1990 price level can be extended to other years using the official rural CPI. Table 2 also reports the cost of the base-year rural living expenditure basket multiplied by the relative change in the official rural CPI between 1990 and 2000 .

As noted earlier, the rural CPI is based on monetary expenses only; that is, it does not give enough weight to those product categories in living expenditures that contain self-produced-self-consumed products. Re-weighting the individual product category price indices within the official rural CPI according to the relative values of the corresponding categories in total rural living expenditures yields an adjusted rural CPI. Table 2 also reports the adjusted rural CPI and the year 2000 basket cost based on the adjusted rural CPI. ${ }^{30}$

\footnotetext{
${ }^{28}$ In contrast, in the case of foods and articles for daily use, the coefficient of variation for the entire category is even lower than the coefficient of variation for the prices of the individual items in all cases except sugar. This suggests that the prices of the individual products within each category do not vary systematically across provinces, with variation of different individual products across provinces canceling out in the category aggregate.

${ }^{29}$ The significance level of the correlation coefficient is determined in an $F(1, N-2)$ test, where $N$ is the number of observations (provinces), and the $F$-value is obtained as "correlation-coefficientsquared" times " $N-2$ " divided by "1 minus correlation-coefficient-squared."

${ }^{30}$ Details on the adjustment of the rural CPI are provided in app. B, Sec. VI.
} 


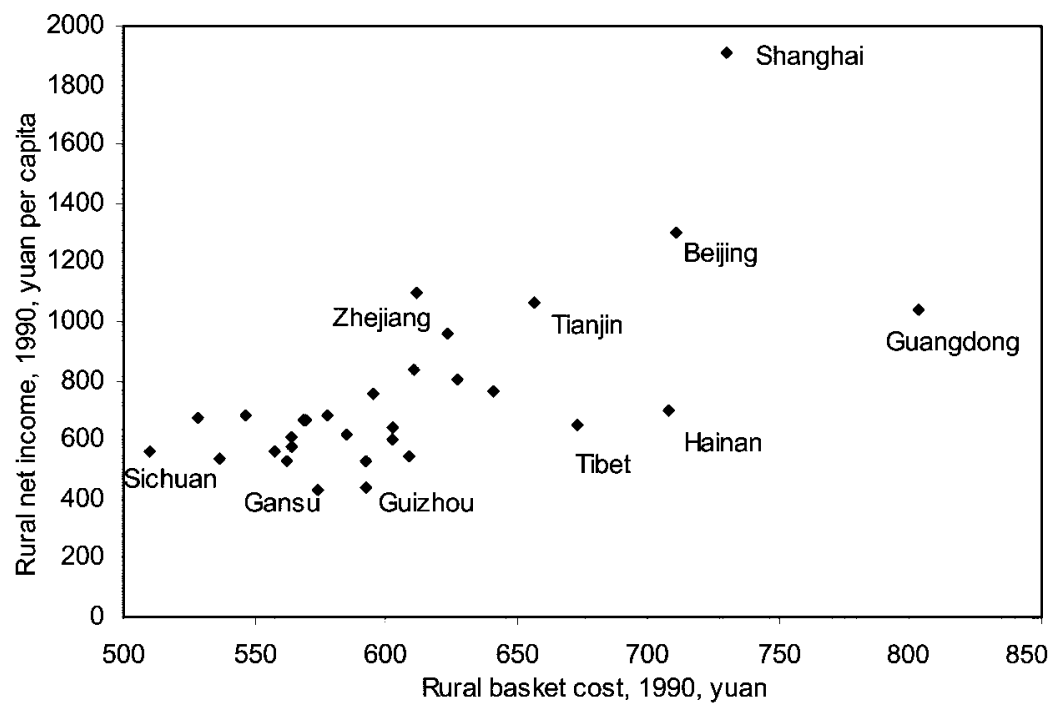

Figure 1. Rural living expenditure basket cost and rural net income (1990 yuan). Sources: See table 2. (Chongqing, lacking a 1990 value, is not included.)

Basket costs for other years, from 1984 through 2004, are provided in the separate spreadsheet.

Given the lack of rural CPIs for Beijing, Tianjin, Shanghai, and Chongqing, and the data problems in the case of Tibet and Hainan (for details, see app. B, Sec. VI, on the adjustment of the rural CPI and app. B, Sec. V, on the provincial-level pricing of the rural basket), in provincial analysis below these six provinces are excluded throughout.

Nationwide, rural prices in 2000 were 2.0290 times their year-1990 level according to the adjusted rural CPI, compared to 1.9025 following the official rural CPI. In other words, the adjusted rural CPI implies slightly higher inflation than the official rural CPI does. But the two rural CPI series are very highly correlated across provinces. ${ }^{31}$ The magnitude of the price increase between 1990 and 2000 differs among provinces: the greatest increase occurred in Guizhou, where prices following the adjusted rural CPI increased by 163\%; in contrast, prices rose by only $81 \%$ in Hebei. We also observe a weak negative

${ }^{31}$ The significance level is .1\%. Without Beijing, Tianjin, Shanghai, Chongqing, Hainan, and Tibet, the correlation coefficient is 0.9016 . For all provinces, it is 0.8608 . As one would expect, the absolute difference between the adjusted rural CPI and the official rural CPI is positively correlated with the share of in-kind consumption in total rural living expenditures in 1990 (1\% significance level). Provinces with a high (low) share of in-kind consumption also have low (high) absolute total living expenditure levels as well as low (high) income levels (.1\% significance level). 
ECONOMIC DEVELOPMENT AND CULTURAL CHANGE

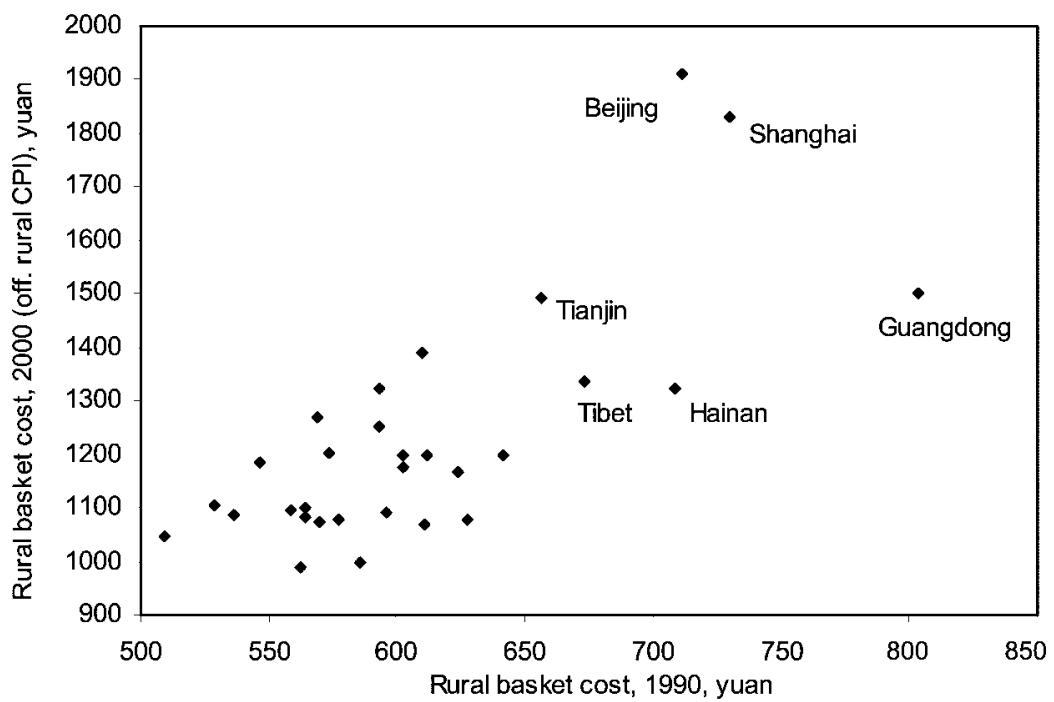

Figure 2. Rural living expenditure basket costs 1990 and 2000. Sources: See table 2. (Chongqing, lacking a 1990 value, is not included.)

correlation between the price increase and the basket cost in the base year. ${ }^{32}$ Nonetheless, a high (low) price level in 1990 means a high (low) price level in 2000, and the price pattern across provinces evident in 1990 persists into the year 2000..33 Figure 2 has the graphical presentation.

The dispersion of price levels across provinces remained almost constant between 1990 and 2000; the coefficient of variation increased only slightly, from 0.0908 to 0.1019 or 0.1109 , depending on the choice of rural CPI (table 2). This implies that prices are not diverging rapidly over time between the rural areas of different provinces. The spread between the provinces with the highest and lowest basket cost between 1990 and 2000 actually narrowed slightly. In 1990, Guangdong (Sichuan) had the most (least) expensive basket, with prices 57.65\% higher in Guangdong. In 2000, the difference between the province with the most expensive basket (Guangdong) and the province with the least expensive basket (Henan) was only 51.91\%. This suggests that the slight increase in the dispersion of the provincial price level is a product of the entire distribution flattening out, as opposed to a widening gap between the provinces in the two tails of the distribution.

${ }^{32}$ Using the adjusted rural CPI, the negative correlation is significant at the $10 \%$ level; however, it is insignificant using the official rural CPI.

${ }^{33}$ The basket costs in the 2 years are positively and significantly correlated. When the official rural CPI is used to obtain the year 2000 values, the significance level is $0.1 \%$; with the adjusted rural CPI it is $10 \%$. 


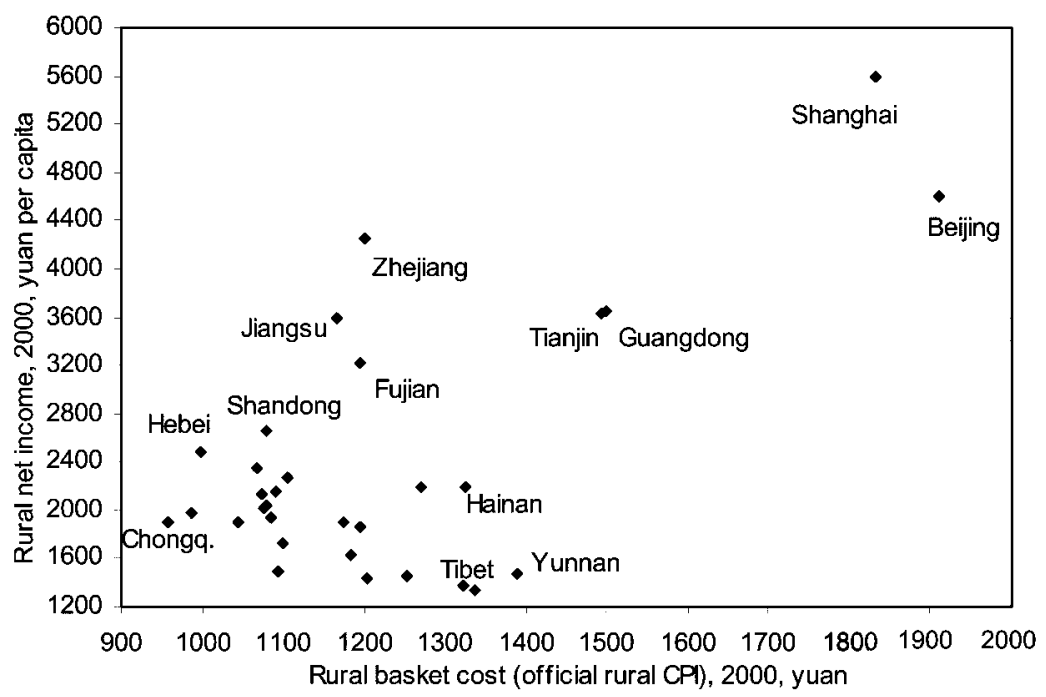

Figure 3. Rural living expenditure basket cost and net income (2000 yuan). Sources: See table 2.

In contrast to 1990 , the year 2000 rural basket cost is not correlated with year 2000 rural net income (as long as the six problematic provinces are excluded from the analysis). In other words, by the year 2000 it was no longer the case that the richest provinces also had the highest prices. ${ }^{34}$ But, as figure 3 shows, the absence of a correlation is in fact due to the presence of two conflicting patterns, with coastal provinces experiencing a strongly positive relationship between basket cost and rural net income in 2000, and interior provinces a slightly negative, or no relationship.

\section{Urban Living Expenditure Price Level}

The procedures for constructing the urban living expenditure basket, pricing it across provinces, and then using the urban CPI to obtain provincial urban price levels in other years are largely identical to the rural case. ${ }^{35}$ Table 4

${ }^{34}$ The correlation coefficient between 1990 and 2000 rural net income is positive and very highly significant. This implies that the random changes in prices between 1990 and 2000 (with respect to the 1990 basket cost) were sufficient to break the correlation between basket cost and rural net income. In other words, between 1990 and 2000 price patterns across provinces, although they remained similar (with statistical significance), changed sufficiently that together with the minor changes in the income patterns the association of high basket costs and high-income levels ended. ${ }^{35} \mathrm{~A}$ few idiosyncrasies in the urban case are explained in app. C, Sec. I, on the construction of the urban basket. In the urban case, more quantity data are available than in the rural case. The Urban Housebold Survey Yearbook 1990 contains the same quantity data as the Statistical Yearbook (various years), plus additional quantity information. The Urban Household Survey Yearbook 1990 reports quantities, values, and unit values. But because the quantities are for broad categories of 
TABLE 4

PER CAPITA URBAN LIVING EXPENDITURE BASKET, 1990

\begin{tabular}{|c|c|c|c|c|c|}
\hline & $\begin{array}{l}\text { Living Expenditures } \\
\text { (Yuan) }\end{array}$ & $\begin{array}{l}\text { Quantity } \\
\text { Consumed }\end{array}$ & $\begin{array}{l}\text { Nationwide Average Price (in Yuan) } \\
\text { per Unit of the Product }\end{array}$ & $\begin{array}{l}\text { Value Covered } \\
\text { (Yuan) }\end{array}$ & $\begin{array}{l}\text { Adjustment } \\
\text { Factor }\end{array}$ \\
\hline $\begin{array}{l}\text { Total } \\
\text { A. Consumer goods } \\
\text { 1. Foods }\end{array}$ & $\begin{array}{c}1,278.89 \\
1,150.8 \\
693.77\end{array}$ & & & & \\
\hline a. Staples & & Kilograms & Implicit Prices & & \\
\hline $\begin{array}{l}\text { i) Implicit, aggregate } \\
\text { ii) Implicit, by type }\end{array}$ & 84.50 & 130.72 & .6464 & $\begin{array}{l}84.50 \\
84.50\end{array}$ & $\begin{array}{l}1.0000 \\
1.0000\end{array}$ \\
\hline Coarse grain (culiang) & 5.13 & 10.69 & 4799 & 5.13 & \\
\hline Wheat flour (mianfen) & 17.05 & 38.56 & .4422 & 17.05 & \\
\hline Rice (dami) & 29.20 & 56.72 & .5148 & 29.20 & \\
\hline Other fine grains (xiliang) & 8.20 & 9.33 & .8789 & 8.20 & \\
\hline $\begin{array}{l}\text { Grain purchased in work unit's cafeteria } \\
\text { Grain purchased from catering }\end{array}$ & 3.45 & 5.75 & .6000 & 3.45 & \\
\hline businesses & 21.47 & 9.67 & 2.2203 & 21.47 & \\
\hline b. Tobacco, alcohol, and tea & 76.07 & Kilograms & Retail Prices & 54.35 & 1.3995 \\
\hline \multicolumn{6}{|l|}{ Alcohol } \\
\hline Spirits (baijiu) & & 3.00 & 2.963 & 8.89 & \\
\hline Beer & & 5.10 & 1.322 & 6.74 & \\
\hline All other alcohol & & 1.15 & 4.489 & 5.16 & \\
\hline Tea leaves & & .24 & 20.0487 (composite) & 4.81 & \\
\hline c. All others & 533.2 & Kilograms & & 466.88 & 1.1421 \\
\hline Fresh vegetables & & $138.70^{\circ}$ & .57 (implicit price) & 79.06 & \\
\hline Dried vegetables & & 3.07 & 3.15 (implicit price) & 9.67 & \\
\hline Edible oil & & 6.40 & 3.20 (implicit price) & 20.48 & \\
\hline Pork & & 18.46 & 5.734 & 105.85 & \\
\hline Beef, lamb & & 3.28 & & & \\
\hline Beef (assume 90\%) & & 3.078 & 6.801 & 20.93 & \\
\hline Lamb (assume 10\%) & & .342 & 6.571 & 2.25 & \\
\hline Poultry & & 3.42 & 7.140 & 24.42 & \\
\hline Eggs & & 7.25 & 5.376 & 38.98 & \\
\hline Fish, shrimp (silver carp) & & 7.69 & 4.185 & 32.18 & \\
\hline Sugar & & 2.14 & 2.6660 (composite) & 5.71 & \\
\hline Fresh melon & & 20.29 & .7200 & 14.61 & \\
\hline Fresh fruit & & 20.82 & 2.9950 (composite) & 62.36 & \\
\hline
\end{tabular}




Dried fruit
Sweets
Cake (pastry)
Milk
Mixed food cans
Other cans
2. Clothing
Cotton cloth
Cotton-chemical fiber mix
Chemical fiber
Nylon
Silk
Bedsheet
Leather shoes
Rubber shoes
Cotton shoes
Plastic shoes
Other shoes (assume sports)
6.
3. Articles for daily use
Small items
Soap (box of 10)
Fragrant or medical soap
Washing powder
Thermos bottle
Aluminum pot
Consumer durables
Bicycle
Sewing machine
Mechanical watch
Clock
Fan
Washing machine
Refrigerator
Cloth stand
Desk
Color TV
Black and white TV
Radio
Photo camera

$\begin{array}{ccc} & 3.21 & \\ & .70 & 5.885 \\ 3.34 & 6.1431 \\ 4.63 & 5.203 \\ .30 & 1.127 \\ .75 & 5.97 \text { (implicit) } \\ & 3.75 \text { (implicit) } \\ 170.90 & 3.129 \\ & .33 \text { meter } & 6.297 \\ 1.46 \text { meter } & 7.765 \\ .26 \text { meter } & 31.7504 \\ .41 \text { meter } & 19.3526 \\ .11 \text { (item) } & 30.549 \\ .61 \text { pairs } & 35.8620 \text { (composite) } \\ .25 \text { pairs } & 13.0300 \\ .49 \text { pairs } & 6.545 \\ .25 \text { pairs } & 3.6998 \\ .69 \text { pairs } & 12.4230 \\ & & \\ & \text { Items } & \\ & & \\ & 6.24 & .935 \\ 1.30 & .862 \\ 1.12 \text { kg } & 1.897 \\ .03 & 5.6085 \\ .03 & 12.2108 \\ \text { Items per } & \\ 100 \text { Persons } & \text { Retail Prices } \\ 3.0971 & 276.786 \\ .1829 & 253.047 \\ 2.2400 & 51.668 \\ 1.5800 & 43.4643 \\ 3.1029 & 273.308 \\ .7229 & 532.965 \\ 1.3314 & 1,697.7572 \\ .1771 & 315.908 \\ .1571 & 202.0268 \\ 1.4286 & 2400.065 \\ .1686 & 540.037 \\ .5714 & 28.852 \\ .4257 & 353.415 \\ & & \end{array}$

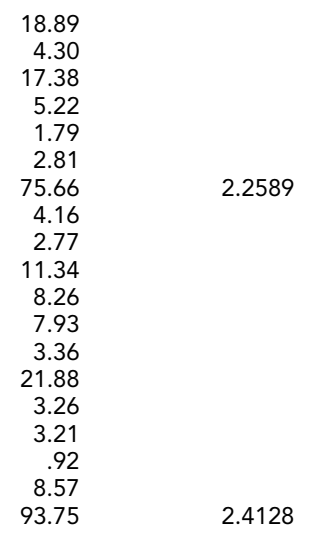

9.61

5.83
1.12

1.12
2.12
.17

.17
.37
84.13

8.57

.46
1.16

.69

8.48
3.85

22.60

$\begin{array}{r}.56 \\ .32 \\ \hline\end{array}$

34.86
.91

.91
.16
1.50 
TABLE 4 (Continued)

\begin{tabular}{|c|c|c|c|c|c|}
\hline & $\begin{array}{l}\text { Living Expenditures } \\
\text { (Yuan) }\end{array}$ & $\begin{array}{l}\text { Quantity } \\
\text { Consumed }\end{array}$ & $\begin{array}{c}\text { Nationwide Average Price (in Yuan) } \\
\text { per Unit of the Product }\end{array}$ & $\begin{array}{l}\text { Value Covered } \\
\text { (Yuan) }\end{array}$ & $\begin{array}{l}\text { Adjustment } \\
\text { Factor }\end{array}$ \\
\hline $\begin{array}{l}\text { 8. Construction materials (housing) } \\
\text { 9. Energy }\end{array}$ & $\begin{array}{l}19.98 \\
20.31\end{array}$ & $.1151 \mathrm{~m}^{2}$ & 173.6636 & & $\begin{array}{l}1.0000 \\
2.0286\end{array}$ \\
\hline Coal & & 206.04 & 4.8592 per $100 \mathrm{~kg}$ & 10.0119 & \\
\hline B. Services & 128.09 & & & & \\
\hline
\end{tabular}

Sources. Living expenditures: Urban Household Survey Yearbook 1990, 20, 120-23; Statistical Yearbook 1991, 281, reports the same living expenditures but then contains slightly different values for some subcategories, with the subcategories in consumer goods almost adding up to the total, but the subcategories in services exceeding the value of services by about $10 \%$ (the item post and telecommunications carries vastly different values in the two sources). Quantities of major consumer goods consumed: value of services by about $10 \%$ (the item post and telecommunications carries vastly different values in the two sources). Quantities of major consumer goods consumed: Yearbook1991. Implicit prices of rural staples, vegetables (fresh and dried), edible oil, and cans of food: Urban Household Survey Yearbook 2000, 120-25, 134-35. Implicit housing costs via construction costs: Investment Materials, 1990-1991, 306, 311. Industrial enterprise employee (zhigong) wage (obtained as total wage bill divided by employees): City Yearbook 1991, 615-24, 635-44.

Note. Published data are reported with as many decimals as in the original source. Four decimals are reported for calculated prices and adjustment factors; in further calculations all decimals are used. Calculated value data are presented with two decimals. All price data except the implicit prices of staples, vegetables (fresh and dried) edible oil, food cans, housing, and services are nationwide retail prices (or a composite thereof). The price of "all other services" is the average annual wage of staff and workers in industrial enterprises. All composite prices are constructed by the authors, with weights chosen by the authors. For further details, including on specific products, see app. C, Sec. I, on the construction of the urban living expenditure basket.

* Annual industrial enterprise wages per laborer. 
reports the urban basket. As in the rural case, it consists of a set of products with product quantities and product category adjustment factors; the relevant nationwide prices are also included. ${ }^{36}$ By design, the urban basket priced at nationwide urban prices equals urban household per capita living expenditures in 1990 .

Table 5 reports the cost in 1990 of the nationwide uniform urban basket in each of China's provinces. Basket costs in years other than 1990 are derived using the urban CPI; year-2000 values are also reported in table 5, while basket costs for all years 1984-2004 are reported in the spreadsheet. Given the lack of price data for Tibet and Hainan, and for Chongqing the lack of the basket cost for 1990 as well as of pre-1997 CPIs, we exclude these provinces in the following provincial analysis. ${ }^{37}$

Between 1990 and 2000, the nationwide average cost of the urban basket increased by $115 \%$, which is slightly higher than the increase in the cost of the rural basket using either the original or the adjusted CPI. Price increases in individual provinces ranged from $169 \%$ in Beijing to $96 \%$ in Henan, a range proportionally larger (relative to the mean increase) than in the rural case. These price changes across urban areas, however, are not systematically correlated with the base-year basket cost; that is, it is not the case that expensive provinces in 1990 experienced particularly high or particularly low inflation in the following years. But the pattern of basket costs across provinces in 2000 remains the same as in 1990 , at the $0.1 \%$ significance level. Provinces with

products, the price data (unit values) are not very meaningful for cross-province comparisons. One special product in the urban case is staples. One price can be obtained implicitly, as in the rural case, from the living expenditure data on staples, combined with the urban quantity of staples consumed. Second, in the urban case, expenditure and quantity data are also available on six exhaustive subcategories of staples, across provinces (which allows the calculation of unit values for subcategories). For each of the six subcategories a nationwide average quantity can thus be priced in each province; i.e., the implicit method is not confined to overall staples but can be extended to six subcategories. Both methods, pricing the average aggregate quantity of staples and pricing each of the six subcategories individually, yield similar results across provinces. The correlation coefficient of the province-specific expenditures using the two pricing methods is significant at the $0.1 \%$ level. The results of both methods are reported in table 4 . The second method is used in the following table (table 5).

${ }^{36}$ As before, nationwide prices are needed to derive the adjustment factors. The specifications of the particular type of nationwide price used for each product in the basket also apply to the provincial-level prices in the pricing of the basket at the provincial level later. The adjustment factors are relatively large for clothing and for articles for daily use. In the case of clothing, more quantity data are available but no matching prices. In the case of articles for daily use, the problem is a lack of quantity data.

${ }^{37}$ For further details on the data problems of these three provinces, see app. C, Sec. II, on the provincial-level pricing of the urban basket; this appendix also provides product-specific pricing details. 
TABLE 5

PRICE LEVEL OF URBAN BASKET ACROSS PROVINCES, 1990 AND 2000, YUAN

\begin{tabular}{|c|c|c|c|c|c|c|c|}
\hline & \multicolumn{2}{|l|}{1990} & \multicolumn{3}{|c|}{2000} & \multicolumn{2}{|c|}{$\begin{array}{l}\text { Reference: Urban } \\
\text { Disposable Income }\end{array}$} \\
\hline & Basket Cost (Yuan) & Ratio & $\begin{array}{l}\text { Urban CPI } \\
2000 / 1990\end{array}$ & $\begin{array}{c}\text { Basket Cost } \\
\text { (Yuan) }\end{array}$ & Ratio & 1990 & 2000 \\
\hline Total & $1,278.89$ & 1.00 & 2.1462 & $2,744.75$ & 1.00 & 1,510 & 6,280 \\
\hline Beijing & $1,295.35$ & 1.01 & 2.6864 & $3,479.79$ & 1.27 & 1,901 & 10,350 \\
\hline Tianjin & $1,188.86$ & .93 & 2.2735 & $2,702.84$ & .98 & 1,628 & 8,141 \\
\hline Hebei & $1,229.92$ & .96 & 2.1162 & $2,602.74$ & .95 & 1,493 & 5,661 \\
\hline Shanxi & $1,326.53$ & 1.04 & 2.2896 & $3,037.24$ & 1.11 & 1,291 & 4,724 \\
\hline Neimenggu & $1,274.64$ & 1.00 & 2.1824 & $2,781.74$ & 1.01 & 1,149 & 5,129 \\
\hline Liaoning & $1,317.85$ & 1.03 & 2.1658 & $2,854.22$ & 1.04 & 1,551 & 5,358 \\
\hline Jilin & $1,288.10$ & 1.01 & 1.9688 & $2,536.02$ & .92 & 1,230 & 4,810 \\
\hline Heilongjiang & $1,314.06$ & 1.03 & 2.1001 & $2,759.66$ & 1.01 & 1,201 & 4,913 \\
\hline Shanghai & $1,410.59$ & 1.10 & 2.5095 & $3,539.86$ & 1.29 & 2,182 & 11,718 \\
\hline Jiangsu & $1,321.36$ & 1.03 & 2.2412 & $2,961.41$ & 1.08 & 1,600 & 6,800 \\
\hline Zhejiang & $1,288.19$ & 1.01 & 2.3555 & $3,034.38$ & 1.11 & 1,917 & 9,279 \\
\hline Anhui & $1,217.38$ & .95 & 2.1873 & $2,662.82$ & .97 & 1,355 & 5,294 \\
\hline Fujian & $1,392.01$ & 1.09 & 2.1444 & $2,985.03$ & 1.09 & 1,655 & 7,432 \\
\hline Jiangxi & $1,287.38$ & 1.01 & 2.1937 & $2,824.12$ & 1.03 & 1,225 & 5,104 \\
\hline Shandong & $1,238.85$ & .97 & 2.2274 & $2,759.41$ & 1.01 & 1,507 & 6,490 \\
\hline Henan & $1,233.92$ & .96 & 1.9593 & $2,417.65$ & .88 & 1,268 & 4,766 \\
\hline Hubei & $1,277.95$ & 1.00 & 2.2879 & $2,923.76$ & 1.07 & 1,427 & 5,525 \\
\hline Hunan & $1,264.73$ & .99 & 2.3110 & $2,922.77$ & 1.06 & 1,439 & 6,219 \\
\hline Guangdong & $1,770.53$ & 1.38 & 2.0032 & $3,546.80$ & 1.29 & 2,303 & 9,762 \\
\hline Guangxi & $1,295.33$ & 1.01 & 2.0103 & $2,604.03$ & .95 & 1,587 & 5,834 \\
\hline Hainan & $1,692.08$ & 1.32 & 2.0342 & $3,442.01$ & 1.25 & 2,303 & 5,358 \\
\hline Sichuan & $1,220.50$ & .95 & 2.2952 & $2,801.27$ & 1.02 & 1,488 & 5,894 \\
\hline
\end{tabular}




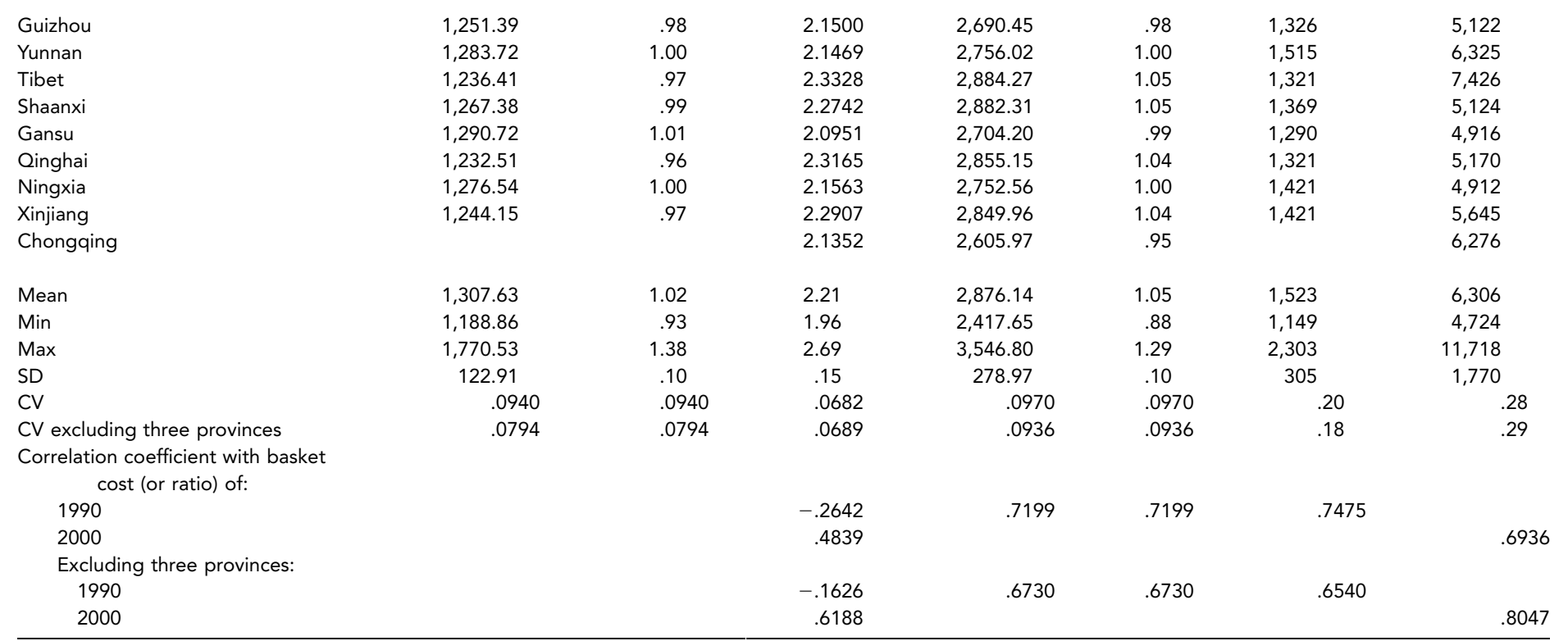

Sources. Base-year prices: same sources as for nationwide prices (table 4). Urban CPI: Statistical Yearbook 1992, 258; 1993, 260; 1994, 241; 1995, 238; 1996, 260; 1997, 271; 1998, 306; 1999, 298; 2000, 294; 2001, 286. Urban disposable income per capita: Urban Household Survey Yearbook 1990, 100, 106, 109 (for the construction of the urban disposable income, see app. A, Sec. II, on income): Statistical Yearbook 2001, 311.

Note. SD: standard deviation. CV: coefficient of variation. "Ratio" denotes the cost of the basket in a particular province relative to the nationwide cost of the basket. The nationwide cost of the basket is based on official nationwide per capita quantity data, as laid out in table 4 (quantities times adjustment factors times prices in table 4 yield the nationwide cost of the basket also reported here). The three provinces excluded in some rows at the bottom are Tibet and Hainan (due to incomplete or poor data) and Chongqing (due to its emergence as provincial-level entity in 1997 only). For the choice of individual prices, see table 4. For further product- and province-specific details, see app. C, Sec. II, on the provincial-level pricing of the urban basket. 
relatively high price levels in 1990 were also the expensive provinces in 2000. (For the correlation coefficients, see the bottom rows of table 5.)

Over the same period, the dispersion of urban price levels across provinces rose slightly, albeit at levels below those of the rural case, with a coefficient of variation of 0.0794 in 1990 and of 0.0936 in 2000. In 1990, the price level was highest in Guangdong, where it was $45.44 \%$ higher than in Anhui, the province with the lowest price level. By comparison, the largest provincial difference in the rural case was the $57.65 \%$ difference between Guangdong and Sichuan. In 2000, the maximum urban gap was the $46.70 \%$ difference between Guangdong and Henan, which is similar in magnitude to the spread between the most and least expensive provinces in 1990. Combined with the slight rise in the coefficient of variation of the basket costs, this implies that within the rather narrow range of price levels, provinces between 1990 and 2000 moved toward the outer boundaries of this range, much as we observed in the rural case.

Tracing the differences in provincial urban basket costs in 1990 back to individual product categories (table 6), some findings are the same as in the rural case ${ }^{38}$ there is very little price variation across provinces in clothing, and least in articles for daily use, while price variation is rather large in the categories housing and energy. The latter two categories, however, account for only a small share of the total basket. In contrast to the rural case, there is less variation in the price of services, measured using average wages of industrial staff and workers, while there is more price variation in foods, especially in staples. ${ }^{39}$ The conclusion is similar to the rural case, in that nontradable goods (and energy) appear to be driving price differences across provinces and that presumably much of the price differences in nontradable goods are due to differences in the price of labor. In the urban case, perhaps due to state regulations, the price of labor (services) does not differ as much across provinces

${ }^{38}$ A longer table tracing the differences in provincial urban basket costs in 1990 back to individual products and product categories, similar to table 3 in the rural case, is provided in app. C, Sec. III.

39 The high price variation in the case of staples could be due to the fact that not all types of staples are grown in every part of China. In the rural case, the aggregate price of staples may have hidden the variation for individual staples, or rural households may predominantly consume local staples (the ones that are cheapest), while urban households may also consume some (more expensive) nonlocal staples. But even the (one) aggregate implicit price of staples shows more price variation across provinces in urban than in rural areas ( 0.2152 vs. 0.1422$)$; a further consideration is that while farmers are likely to purchase grain and to grind it into flour themselves, urban households are likely to purchase grain in the form of flour, noodles, or steamed rice in the cafeteria (which have an extra labor/service component to them); i.e., the exact product specifications differ from rural to urban households. 
as in the rural case. In the urban case, furthermore, food prices, in the aggregate, vary significantly more than in the rural case.

The 1990 urban basket cost is highly correlated with urban disposable income. In other words, the most (least) expensive provinces had the highest (lowest) urban disposable income. In contrast to the rural case, where the relationship by 2000 split broadly into a positive coastal-region relationship versus a slightly negative or no interior-region relationship, in the urban case the positive correlation was even stronger by 2000 (with the significance level in both years below 0.1\%). (Also see fig. 4 for 2000.) Provinces with high (low) disposable income consistently face high (low) price levels. ${ }^{40}$

\section{Living Expenditure Price Levels Based on a Joint Rural-Urban Basket}

The joint basket involves (i) nationwide average per capita product quantities, (ii) nationwide average product prices, and (iii) nationwide category-specific adjustment factors. (i) The nationwide average per capita quantity of a product (joint quantity) is obtained as the rural per capita quantity times the rural share of the population, plus the urban per capita quantity times the urban share of the population. (ii) To obtain the nationwide average price of a product requires two steps. In a first step, the nationwide average per capita expenditure on the product (joint expenditure) is obtained as rural average per capita expenditure (rural quantity times rural price) times the rural share of the population, plus the urban average per capita expenditure times the urban share of the population. In a second step, dividing the nationwide average per capita expenditure on the product by the nationwide average per capita quantity of the product yields the nationwide average product price (joint price). (iii) Summing joint expenditures across products within one category and comparing the sum to the official joint living expenditures in this category reveals the necessary adjustment factor.

Due to a number of data complications, this ideal procedure cannot always be followed. Details on the ways in which the different data complications are addressed, approximating the above procedure as much as possible, are relegated to an appendix, which also presents the joint basket similar to the rural basket in table 1 and the urban basket in table $4 .{ }^{41}$ Once the joint basket is

${ }^{40}$ The following relationships were also charted and checked visually for outliers that could strongly influence correlation coefficients: the relationship between the 1990 urban basket cost and 1990 urban disposable income, the relationship between the 1990 urban basket cost and the urban CPI (of 2000 compared to 1990), and the relationship between 1990 and 2000 urban basket costs. Outliers were present in all cases, but their removal, while it might weaken the relationship, would not alter it significantly.

${ }^{41}$ See app. D, on the construction of the joint basket and provincial-level pricing of the joint basket, and app. A, Sec. VI, on issues with the population data. 
TABLE 6

DRIVING FACTORS OF DIFFERENCES IN URBAN PRICE LEVELS ACROSS PROVINCES, 1990

\begin{tabular}{|c|c|c|c|c|c|c|}
\hline \multirow[b]{2}{*}{ S } & \multirow[b]{2}{*}{$\begin{array}{l}\text { National } \\
\text { Product Price }\end{array}$} & \multicolumn{5}{|c|}{ Across Provinces: Individual Item or Category Price } \\
\hline & & Mean & Min & $\operatorname{Max}$ & SD & $\mathrm{CV}$ \\
\hline \multicolumn{7}{|l|}{ Total } \\
\hline \multicolumn{7}{|l|}{ A. Consumer goods $(89.98 \%)$} \\
\hline $\begin{array}{l}\text { 1. Foods }(54.25 \%) \\
\text { a. Staples }(6.61 \%)\end{array}$ & 693.77 & 716.63 & 606.88 & $1,090.22$ & 102.83 & .1435 \\
\hline $\begin{array}{l}\text { i) Aggregate, implicit } \\
\text { ii) Implicit, by type }\end{array}$ & .64 & .64 & .45 & 1.15 & .14 & .2152 \\
\hline Coarse grain (culiang) & .48 & .84 & .32 & 1.53 & .40 & .4748 \\
\hline Wheat flour (mianfen) & .44 & .47 & .38 & .97 & .12 & .2527 \\
\hline Rice (dami) & .51 & .59 & .30 & 1.09 & .26 & .4355 \\
\hline Other fine grain (xiliang) & .88 & .91 & .59 & 1.94 & .26 & .2886 \\
\hline Grain purchased in work unit's cafeteria & .60 & .78 & .32 & 1.82 & .45 & .5809 \\
\hline Grain purchased from catering businesses & 2.22 & 2.42 & 1.41 & 4.57 & .77 & .3191 \\
\hline b. Tobacco, alcohol, tea (5.95\%) & 56.53 & 55.12 & 41.58 & 80.22 & 7.65 & .1387 \\
\hline c. All others $(41.69 \%)$ & 465.93 & 475.24 & 394.32 & 724.00 & 68.90 & .1450 \\
\hline 2. Clothing $(13.36 \%)$ & 75.66 & 78.12 & 62.86 & 96.11 & 8.42 & .1078 \\
\hline
\end{tabular}


3-6 (17.69\%)

3. Articles for daily use $(10.14 \%)$

93.75

93.61

85.66

109.39

5.73

.0612

5. Books, newspapers, magazines $(0.87 \%)$

6. Other goods (1.34\%)

7. Medicine and medical articles (1.54\%)

8. Construction materials (1.56\%)

Construction costs per square meter

9. Energy (1.59\%)

Coal

\section{B. Services $(10.02 \%)$}

1. Gas $(0.20 \%)$

Liquefied petroleum gas

All other services $(9.81 \%)$

Wages of individual staff and workers

$\begin{array}{rr} & \\ 19.65 & 19.63 \\ 19.98 & 19.81 \\ 173.66 & 172.21 \\ 10.01 & 9.92 \\ 7.95 & 4.82 \\ & \\ 6.50 & 6.72 \\ .76 & .76 \\ 125.47 & 126.40 \\ 2,278.20 & 2,295.07\end{array}$

Sources. See table 4.

$2,295.07$

\begin{tabular}{rrrrr}
19.63 & 13.86 & 25.46 & 2.49 & .1270 \\
19.81 & 11.43 & 29.60 & 5.91 & .2981 \\
172.21 & 99.34 & 257.25 & 51.33 & .2981 \\
9.92 & 6.18 & 16.51 & 2.82 & .2844 \\
4.82 & 3.00 & 8.01 & 1.37 & .2844 \\
& & & & \\
6.72 & 1.77 & 22.98 & 4.49 & .6672 \\
.76 & .20 & 2.60 & .51 & .6672 \\
126.40 & 99.82 & 172.28 & 15.66 & .1239 \\
295.07 & $1,812.53$ & $3,128.09$ & 284.26 & .1239 \\
\hline
\end{tabular}

Note. SD: standard deviation. CV: coefficient of variation. The full table of driving factors, including all individual products, is reported in app. C, Sec. III. For the units of individual products, see table 4. The percentages given in parentheses after the labels of the main product categories are the shares of these product categories in total urban living expenditures. For the absolute values, see table 4. When a national price for a product is lacking, the arithmetic mean across all provinces is used, including provinces whose values were imputed. (Chongqing data are never available and are not imputed.) The statistics for the price of foods cover the sum of the "implicit price times quantity" of staples and the aggregate prices (values) of the other two categories within foods, namely, "tobacco, alcohol, and tea" and "all others," with the latter two categories weighted by their adjustment factor. All other category prices do not incorporate adjustment factors. The underlying prices for the categories "medicine and medical articles," "construction materials," "energy," and "all others" within services are implicit prices (i.e., their adjustment factor would be unity). 
ECONOMIC DEVELOPMENT AND CULTURAL CHANGE

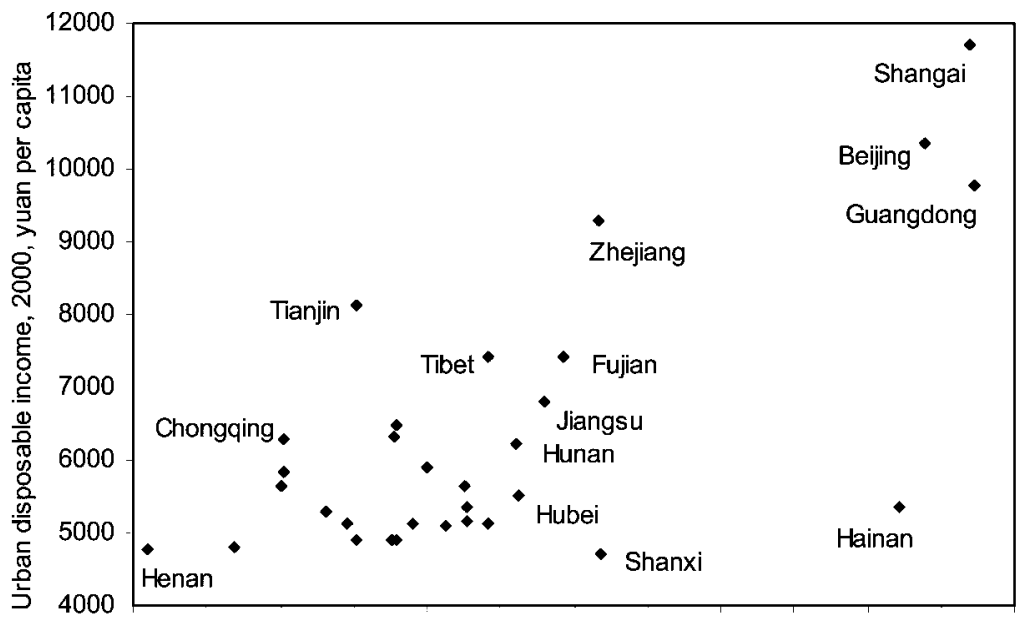

$2400250026002700280029003000310032003300 \quad 3400 \quad 3500 \quad 3600$

Urban basket cost, 2000 , yuan

Figure 4. Urban living expenditure basket cost and disposable income (2000 yuan). Sources: See table

established, it can be priced across provinces at provincial-level rural prices (as the rural basket was before), at provincial-level urban prices (as the urban basket was before), or at provincial-level joint prices (covering the whole province).

Table 7 reports the year 1990 nationwide and provincial-level costs of the joint basket in rural areas (priced at rural prices), in urban areas (priced at urban prices), and province-wide (priced at joint prices). Year-2000 data are obtained by multiplying the 1990 basket cost by the appropriate price index. When rural prices are used to price the joint basket, this is the rural CPI, both in official and adjusted form. When urban prices are used to price the joint basket, this is the urban CPI. When joint (i.e., provincial average) prices are used to price the joint basket, this is the provincial CPI. ${ }^{42}$ Table 7 also reports the year-2000 joint basket cost (with two year-2000 values in the rural case, based on the official and the adjusted rural CPI). The basket costs of all years 1984-2004 are included in the spreadsheet.

42 In the case of the provincial CPI, no adjustments to give proper weight to the rural selfproduced-self-consumed living expenditures are made. The impact in the rural case of using an adjusted rather than the official rural CPI was relatively minor and can only be smaller in the joint case. It can only be smaller, because the relative size of the missing rural self-produced-self-consumed living expenditures in the provincial CPI is smaller than in the rural CPI (rural self-produced-selfconsumed living expenditures represent one-third of total rural living expenditures and less than that of population-weighted nationwide joint living expenditures). 
In provincial-level analysis below, provinces with problematic data are omitted; these are the three provinces Tibet, Hainan, and Chongqing when the joint basket is priced at urban or joint prices, and, in addition, Beijing, Tianjin, and Shanghai when the joint basket is priced at rural prices (where in table 7, by necessity, provincial CPIs are used to derive year 2000 values).

The pattern of price levels across provinces is the same when the joint basket is priced at rural prices as when the rural basket is priced at rural prices. This is also true for the urban case. ${ }^{43}$ Most results of the rural basket, priced at rural prices, and the urban basket, priced at urban prices, carry over to the case of the joint basket priced at rural and urban prices.

Thus, the dispersion of price levels across provinces, as before, rises between 1990 and 2000, slightly in the rural and urban case (from a coefficient of variation of 0.0860 to 0.1009 or 0.1118 , and from 0.1093 to 0.1256 ), but by $47.53 \%$ in the provincial case (from 0.0930 to 0.1372 ). At the same time, the relative range of basket costs across provinces falls over time at all three pricing regimes. ${ }^{44}$ The pattern of increasing dispersion and decreasing range implies that while the provinces with the lowest and highest price levels move closer to the mean price level as time progresses, the individual provinces, within this range, move outward toward the (inward-moving) boundary price levels over time. This is true for rural areas, for urban areas, and for provinces in total.

As in the case of the rural and the urban baskets, the three CPIs in the case of the joint basket are not correlated with base-year price levels in rural areas, urban areas, or province-wide, that is, it is not the case that provinces with the highest price levels in 1990 experienced the highest price increases over the next decade. But the 1990 pattern of basket cost across provinces persisted into 2000 (except at rural prices using the adjusted CPI); expensive

${ }^{43}$ For simplicity, also in the following, a statement to the effect that pattern $\mathrm{A}$ is the same as pattern B means that the correlation coefficient between the two time series is significantly positive. In the rural and urban case here, with all correlation coefficients above 0.9, the significance level is well below $0.1 \%$. The correlation coefficients cover 10 combinations: rural basket 1990 vs. joint basket at rural prices 1990, the same for 2000 using both rural CPIs; the previous three combinations without the six problematic provinces; urban basket 1990 vs. joint basket at urban prices 1990, the same for 2000; and the previous two combinations without the three problematic provinces. ${ }^{44}$ When the joint basket is priced at rural prices, the highest price level in 1990 exceeds the lowest one by $56.09 \%$, and in 2000 by $51.75 \%$ (based on the official rural CPI) or $48.05 \%$ (based on the adjusted rural CPI), i.e., the range is reduced, as in the case of the rural basket priced at rural prices before. The range is also reduced in the urban case (from 64.88\% in 1990 to $51.70 \%$ in 2000), where it was constant in the case of the urban basket priced at urban prices, and it is finally reduced in the provincial case (from $56.29 \%$ to $48.50 \%$ ). 
TABLE 7

JOINT EXPENDITURE BASKET PRICE LEVELS, 1990 AND 2000, YUAN

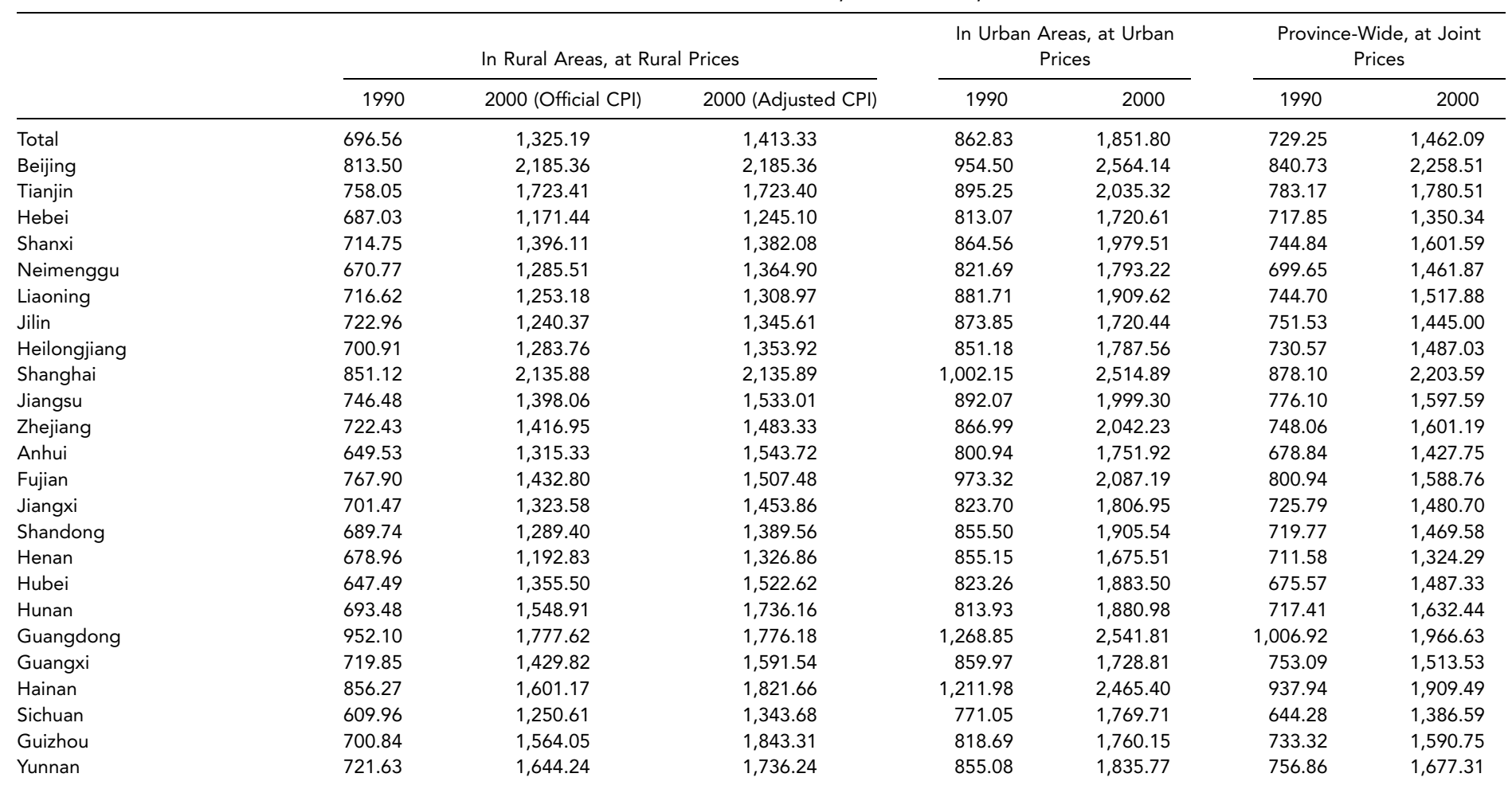




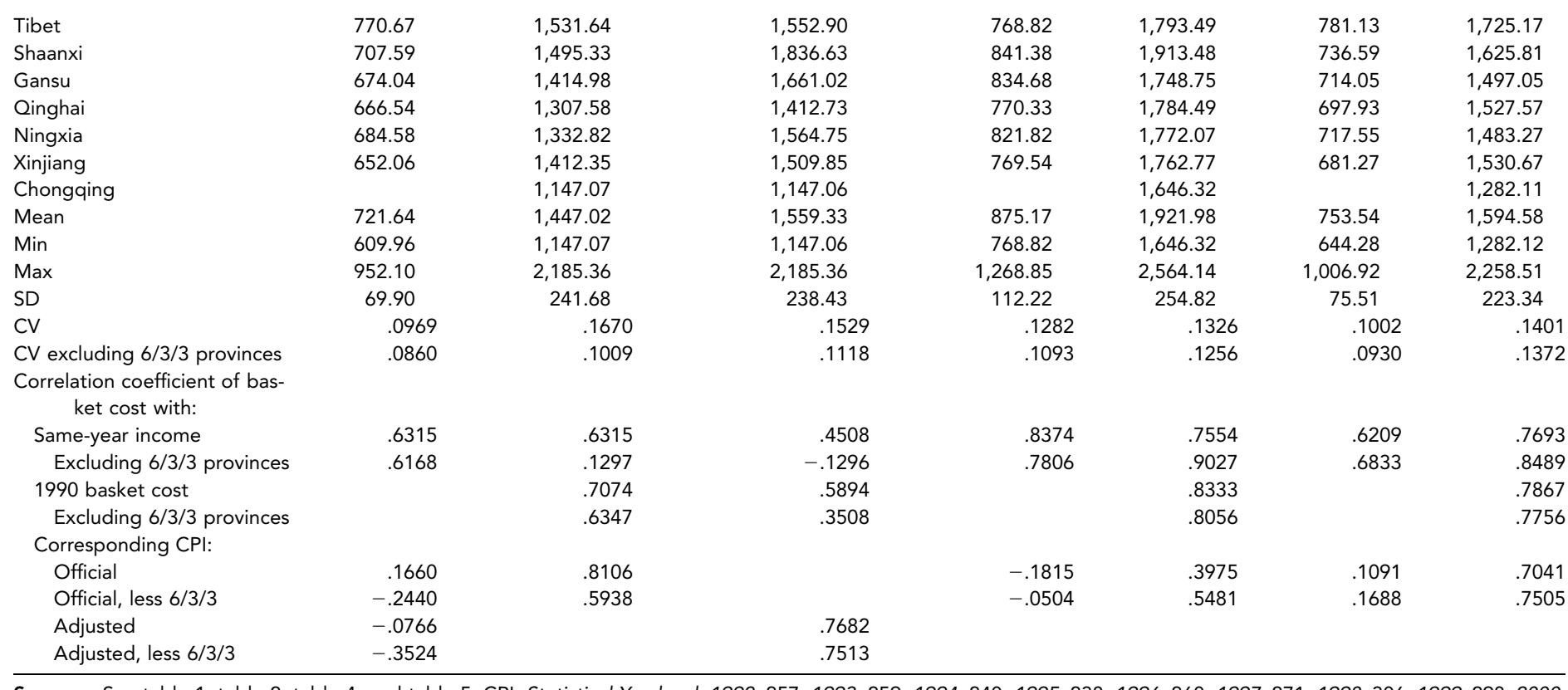

Sources. See table 1, table 2, table 4, and table 5; CPI: Statistical Yearbook 1992, 257; 1993, 259; 1994, 240; 1995, 238; 1996, 260; 1997, 271; 1998, 306; 1999, 298; 2000 294; 2001, 286.

Note. SD: standard deviation. CV: coefficient of variation. 6/3/3 provinces: six provinces in the rural case (Tibet, Hainan, Chongqing, Beijing, Tianjin, and Shanghai), three provinces in the urban case (Tibet, Hainan, and Chongqing), and the same three provinces in the province-wide case. "Same-year income," in a row at the bottom of the table, is the income of the same year for which basket costs are listed in the columns. In the last two columns of this row, basket costs at joint prices are correlated with the population-weighted mean of rural net income and urban disposable income. Also see notes to table 2 and table 5 . Further details on the joint basket, including its establishment and provincial-level pricing, are provided in app. D. 
localities in 1990 remained expensive localities in $2000 .{ }^{45}$ Also as in the case of the rural and the urban baskets, price levels are positively correlated with same-year income throughout, at rural prices, at urban prices, and at joint prices, in 1990 and in 2000, except at rural prices in 2000 (as in the case of the rural basket before).

The joint basket also allows a direct comparison of rural and urban areas within any one province. These comparisons are taken up in the following section.

\section{Implications of Spatial Price Differences}

What are the implications of spatial differences in the cost of living in our analysis? In order to see how important they can be, we provide two straightforward examples.

First, spatial differences in price levels matter for inequality measures. Provincial differences in per capita incomes are usually identified as an important component of overall income inequality. Yet, as we noted earlier, incomes and prices are often positively correlated, which may bias these calculations. In table 8 we present the Gini coefficients for provincial-level mean rural and urban per capita incomes, with and without the correction to the income levels using the new spatial deflators. For comparison, we also report results using the coefficient of variation, an alternative measure of income dispersion, as well as the ratio of per capita income in the richest to the poorest province. We also calculate our inequality measures for rural and urban areas using the joint basket (as opposed to the separate baskets).

These inequality measures assume that every individual in a province (or rural or urban area of a province) has the same amount of income. That is, the inequality measures do not measure inequality across individuals but across provincial (or provincial rural or urban) means. They provide an estimate of the inequality in incomes across provinces, ignoring income differences within provinces.

In 1990, the Gini coefficient for provincial per capita rural net income was 0.134 . Because rural prices tended to be higher in high-income provinces, the Gini coefficient overestimates the degree of interprovincial inequality. Once we spatially deflate the data, the Gini coefficient falls to 0.105 , a decline of almost 30\%. In 2000, however, the Gini coefficient is 0.169 without deflating and only marginally lower at 0.163 with spatial deflating. This much smaller

45 The existence of a correlation usually comes with a significance level of $0.1 \%$ or $1 \%$; the absence of a correlation means no significance at the $10 \%$ level. For simplicity, individual significance levels are not mentioned in the text. They can be calculated from the correlation coefficients reported in table 7. For the calculation of the significance level, see n. 30 . 
TABLE 8

PROVINCIAL

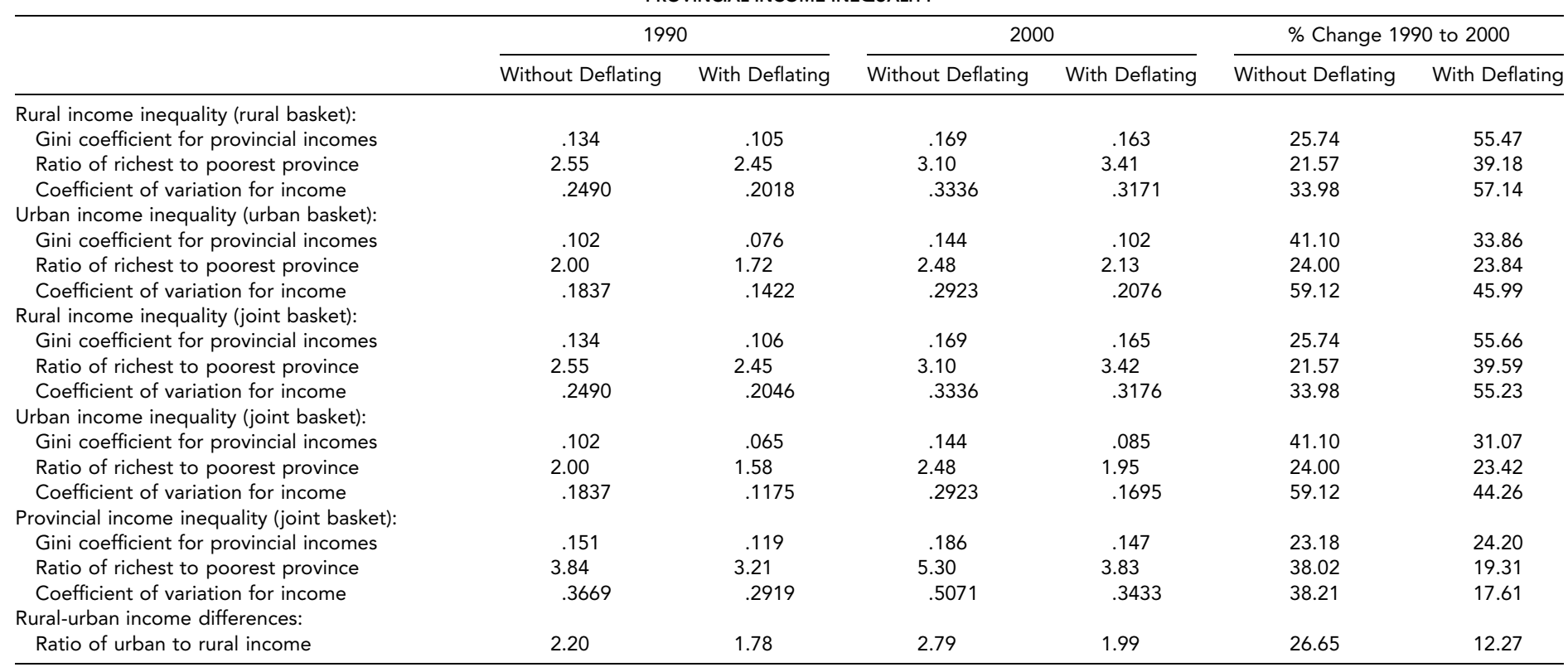

Sources. Table 2, table 5, table 7, and appendices on income and population data (app. A, Sec. II, and app. A, Sec. VI, respectively).

Note. The six (three) problematic provinces in the rural (urban and joint) case are omitted. To obtain the rural spatial deflators for 2000, the official rural CPI was used. All Gini coefficients are population-weighted. The Gini coefficients, in the case "without deflating," are calculated using the per capita rural net income (or urban disposable income, or provincial-level population-weighted income) in each province weighted by the size of the rural (urban, provincial) population. In the case "with deflating," the income measures are first spatially deflated. The ratio of urban to rural income, e.g., in 1990 with deflating, is obtained as the nationwide ratio of "urban per capita disposable income in 1990 to urban basket cost in 1990" (1,510/862.83), divided by the nationwide ratio of "rural per capita net income in 1990 to rural basket cost in 1990" (686/696.56), 
effect of deflating on the Gini coefficient reflects the fact that by 2000 there was no systematic correlation between per capita rural net income levels and the provincial rural price levels. The similarity in the Gini for 2000 with and without deflating also implies that the increase in provincial inequality between 1990 and 2000 is significantly larger when incomes are spatially deflated than when they are not $(55.5 \%$ vs. $25.7 \%)$.

In the urban case, however, spatially deflating the income data reduces significantly both the 1990 Gini coefficient, from 0.102 to 0.076 , and the 2000 Gini coefficient, from 0.144 to 0.102 . In contrast with rural incomes, the growth in provincial-level inequality across provinces is lower when urban incomes are spatially deflated.

In table 8 , we also report inequality measures at the provincial level that use the joint basket, priced at the provincial level, to spatially deflate provincial average per capita income. Similar to the urban case, this reduces the Gini coefficient and the other measures of inequality significantly both in 1990 and in 2000 .

In general then, the changes in the Gini coefficient when income is spatially deflated show that a failure to deflate spatially leads to a-at times heavilybiased estimate of the degree of inequality at a given point in time. The magnitudes of the changes in inequality that occur over time are also affected. Inequality rose more drastically across rural areas in different provinces than previously thought, but less rapidly across urban areas than previously thought.

Second, spatial differences in price levels affect rural-urban income differences. The joint basket allows a direct comparison of incomes in rural and urban areas within each province. In 1990, the ratio of nationwide per capita urban disposable income to nationwide per capita rural net income was $2.20 .^{46}$ In other words, urban per capita income was 2.20 times larger than rural per capita income. By 2000, the ratio increased to 2.79. Yet, these calculations fail to adjust for differences in the cost of living between rural and urban areas. In 1990 , the cost of the joint basket was on average $23.9 \%$ higher in urban areas than in rural areas, while by 2000 the difference had widened to $39.7 \%$. Once adjusted for these differences in purchasing power, the gap in urbanrural incomes in 1990 falls from 2.20 to 1.78 and in 2000 from 2.79 to 1.99 . These revised estimates by no means eliminate the gap, but they suggest that it is significantly smaller than the official income data indicate and, furthermore, between 1990 and 2000, increased by $12.3 \%$ rather than $26.7 \%$.

\footnotetext{
46 The values discussed here are nationwide values, i.e., covering all provinces. Similar comparisons are possible at the provincial level. The urban-rural income difference calculated here is subject to the measurement differences inherent in the official income data as outlined in Sec. II and further explained in app. A, Sec. II, on income data.
} 


\section{Conclusions}

Differences in price levels across provinces matter for economic outcomes such as inequality and should be taken into account in all cross-province comparisons that involve measures of income (or GDP). Thanks to absolute price data available for a limited set of products in the early 1990s, we were able to construct comparable, absolute prices of the typical household living expenditure basket for each province in China in 1990. We create a time series of absolute provincial price levels for the years 1984-2004 by using annual consumer price indices.

These spatial deflators make a significant difference to measures of inequality, more often than not reducing inequality. They also yield differentiated results as to the relative changes in inequality over time. Given their significant impact in our straightforward applications, spatial deflators should probably become part of every inequality study. Spatial deflation is particularly urgent in a country such as China due to its large geographic area with potentially segmented markets and due to its household registration system that hampers nationwide labor market integration and thereby convergence in the price of nontradables.

Our spatial deflators are not without shortcomings. It would have been ideal to price the basket at absolute prices every year and, in a further step, to make adjustments to the basket every year or every few years, in accordance with nationwide changes in living expenditure patterns, but the absolute price data are simply not available. Our calculations have involved a range of assumptions from the choice of the price specification for particular products to the choice of population weights, implicit versus composite pricing methods, and the handling of missing data. We have to live with a number of constraints, such as the use of the official CPI to derive price levels for other years, and official imputation prices for self-produced-self-consumed rural living expenditures in $1990 .^{47}$

With every choice we made we tried to check for the robustness of the method that we chose by also pursuing alternative paths whenever possible. Some of the robustness checks are mentioned in notes, while many others are reported in the appendices (available in the online version), where we also tried to document every step in our calculations and to justify every choice we made.

A next step forward is only possible with more absolute price and quantity data across provinces for 1990 and, probably even more importantly, absolute

\footnotetext{
${ }^{47}$ Detailed considerations of potential biases in our data and calculations are provided in app. A, Sec. VII. A comparison of our procedure to that of Deaton (2003) and Deaton and Tarozzi (2000) in the case of India is provided in app. A, Sec. VIII.
} 
price data across provinces in other years. These data would have to be newly released by the NBS and/or the price bureau of the (current) State Development and Reform Commission. In all likelihood, consistent time series of prices for specific products over 2 decades do not exist. If they did, the data work, including the regular construction of updated baskets, would probably require a long-term commitment by a group of researchers or Chinese statistics officials. Ex ante, it is difficult to know how much of an improvement more price and quantity data might allow over our base-year basket with application of CPIs for other years. For the time being, we hope that the spatial deflators we provide help qualify research results that are based on cross-provincial comparisons in China, such as inequality studies.

\section{References}

Adelman, Irma, and David Sunding. 1987. "Economic Policy and Income Distribution in China." Journal of Comparative Economics 11, no. 3 (September): 441-61.

Bishop, John A., John P. Formby, and Zheng Buhong. 1996. "Regional Income Inequality and Welfare in China: A Dominance Analysis." Asian Economic Journal 10, no. 3 (November): 239-69.

BLS (Bureau of Labor Statistics). 2000. "Understanding the Consumer Price Index: Answers to Some Questions." Revised. U.S. Department of Labor, Bureau of Labor Statistics, Washington, DC. Also on the Web as "Frequently Asked Questions," at http://www.bls.gov./cpi/cpifaq.htm.

Chen, Shaohua, and Martin Ravallion. 1996. "Data in Transition: Assessing Rural Living Standards in Southern China." China Economic Review 7, no. 1:23-56.

City Yearbook 1991. 1991. Zhonguo chengshi tongji nianjian 1991 [China city statistical yearbook, 1991]. Guo jia tong ji ju zong he si [Comprehensive Division, National Bureau of Statistics]. Beijing: Zhongguo tongji chubanshe.

Deaton, Angus. 2003. "Prices and Poverty in India, 1987-2000." Economic and Political Weekly (January 25): 362-68.

Deaton, Angus, and Alessandro Tarozzi. 2000. "Prices and Poverty in India." Unpublished manuscript, Research Program in Development Studies, Princeton University (July).

Gustafsson, Björn, and Shi Li. 1998. "Inequality in China at the End of the 1980s: Locational Aspects and Household Characteristics." Asian Economic Journal 12, no. 1 (March): 35-63.

Howes, Stephen. 1993. "Income Inequality in Urban China in the 1980s: Levels, Trends and Determinants." Development Economics Research Programme, Series on Economic Transformation and Public Finance, EF no. 3, London School of Economics (July).

Hsiung, Bingyuang, and Louis Putterman. 1989. "Pre- and Post-reform Income Distribution in a Chinese Commune: The Case of Dahe Township in Hebei Province." Journal of Comparative Economics 13, no. 3 (September): 406-45.

Investment Materials, 1990-1991. 1993. Zhongguo guding zichan touzi tongji ziliao 1990-1990 [Statistical materials on fixed asset investment in China, 1990-1991]. 
Guojia tongjiju guding zichan touzi tongji si [Investment in Fixed Assets Statistical Division, National Bureau of Statistics]. Beijing: Zhongguo tongji chubanshe.

Kanbur, Ravi, and Xiaobo Zhang. 2004. "Fifty Years of Regional Inequality in China: A Journey through Central Planning, Reform and Openness." Research Paper no. 2004/50. World Institute for Development Economics, United Nations University (August).

Khan, Azizur Rahman, Keith Griffin, and Carl Riskin. 1999. "Income Distribution in Urban China during the Period of Economic Reform and Globalization." American Economic Review 89, no. 2 (May): 296-300.

Khan, Azizur Rahman, Keith Griffin, Carl Riskin, and Zhao Renwei. 1992. "Household Income and Its Distribution in China." China Quarterly, no. 132 (December): 1029-61.

- 1993. "Source of Income Inequality in Post-reform China." China Economic Review 4, no. 1 (Spring): 19-35.

Khan, Azizur Rahman, and Carl Riskin. 1998. "Income and Inequality in China: Composition, Distribution and Growth of Household Income, 1988 to 1995." China Quarterly, no. 154 (June): 221-53.

Knight, John, and Lina Song. 1990. "The Spatial Contribution to Income Inequality in Rural China." Oxford Applied Economics Discussion Paper, no. 106, Institute of Economics and Statistics, University of Oxford (November).

- 1991. "The Determinants of Urban Income Inequality in China." Oxford Bulletin of Economics and Statistics 53, no. 2 (May): 123-54.

Kravis, Irving B., and Robert E. Lipsey. 1988. "National Price Levels and the Prices of Tradeables and Nontradeables." American Economic Review (AEA Papers and Proceedings) 78, no. 2 (May): 474-78.

Liu, Chengxiang, Liu Ke, and Jin Zhaofeng. 2000. Ruhe shiyong tongji nianjian [How to use the statistical yearbook]. Beijing: Zhongguo tongji chubanshe.

Lyons, Thomas P. 1998. "Intraprovincial Disparities in China: Fujian Province, 1978-1995." Economic Geography 74, no. 4 (October): 405-32.

Meng, Xin, Robert Gregory, and Youjuan Wang. 2005. "Poverty, Inequality, and Growth in Urban China, 1986-2000.” Unpublished manuscript, Department of Economics, Australian National University (May). Accessed on April 2, 2006, at http://www.caer.unsw.edu.au/DevelopementWorkshop05/Meng.pdf.

Meng, Xin, and Harry X. Wu. 1998. "Household Income Determination and Regional Income Differential in Rural China." Asian Economic Journal 12, no. 1 (March): 65-88.

Price Statistical Yearbook. Various years. Zhonguo wujia tongji nianjian [China price statistical yearbook]. Guo jia tong ji ju cheng shi she hui jing ji diao cha zong dui [National Urban Social and Economics Survey Team, National Bureau of Statistics]. Beijing: Zhongguo tongji chubanshe.

Ravallion, Martin, and Shaohua Chen. 2004. "China's (Uneven) Progress against Poverty.” World Bank Policy Research Working Paper no. 3408 (September). Available at Social Science Research Network: http://ssrn.com/abstract $=625285$.

Rozelle, Scott. 1994. "Rural Industrialization and Increasing Inequality: Emerging 
Patterns in China's Reforming Economy." Journal of Comparative Economics 19, no. 3 (December): 362-91.

Rural Household Survey Yearbook. Various years. Zhongguo nongcun zhubu diaocha nianjian [China rural household survey yearbook]. Guo jia tong ji ju nongcun she hui jing ji diao cha zong dui [National Rural Social and Economic Survey Team, National Bureau of Statistics]. Beijing: Zhongguo tongji chubanshe.

Rural Statistical Yearbook. Various years. Zhongguo nongcun tongji nianjian [China rural statistical yearbook]. Guo jia tong ji ju nong ye tong ji si [Agricultural Statistics Division, National Bureau of Statistics]. Beijing: Zhongguo tongji chubanshe.

Statistical Yearbook. Various years. Zhongguo tongji nianjian [Statistical yearbook]. Guojia tongji ju [National Bureau of Statistics]. Beijing: Zhongguo tongji chubanshe.

Trescott, Paul B. 1985. "Incentives versus Equality: What Does China's Recent Experience Show?" World Development 13, no. 2 (February): 205-17.

TVE Yearbook. Various years. Zhongguo xiangzhen qiye nianjian [China township (and village) enterprise yearbook]. Zhongguo xiangzhen qiye nianjian bianji weiyuanhui [China Township and Village Enterprise Yearbook Editorial Committee]. Beijing: Zhongguo nongye chubanshe.

Urban Housebold Survey Yearbook. Various years. Zhongguo chengzhen jumin jiating shouzhi diaocha ziliao [China urban resident household income and expenditure survey material]. Guo jia tong ji ju cheng shi she hui jing ji diao cha zong dui [National Urban Social and Economic Survey Team, National Bureau of Statistics]. Annual publication. Beijing: Zhongguo tongji chubanshe. Beginning with the 1996 edition the title is Zhongguo wujia ji chengzhen jumin jiating shouzhi diaocha tongji nianjian [China material price and urban household expenditure survey statistical yearbook].

Wei Shang-jin, and Wu Yi. 2001. "Globalization and Inequality: Evidence from Within China.” NBER Working Paper Series, no. 8611, National Bureau of Economic Research, Cambridge, MA (November).

Yang, Dennis Tao. 1999. "Urban-Biased Policies and Rising Income Inequality in China." American Economic Review 89, no. 2 (May): 306-10.

Zhang Xiaobo, and Ravi Kanbur. 2001. "What Difference Do Polarisation Measures Make? An Application to China.” Journal of Development Studies 37, no. 3 (February): 85-98. 